\section{Ang senyas: Diskurso ng pagkabansa mula sa mga pangunahing materyal na icon sa 29 na mga obra ng siningsaysay}

Capulla, Rose Pascual $₫$

Visayas State University, Philippines (rosecapulla2018@gmail.com)

Demeterio, Feorillio Petronilo A. III

De La Salle University - Manila, Philippines (feorillio.demeterio@dlsu.edu.ph)

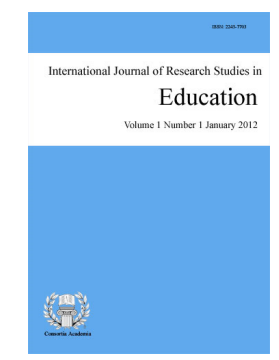

ISSN: 2243-7703 Online ISSN: 2243-7711

OPEN ACCESS

\title{
Abstract
}

History Art is a powerful force that shaped the nationhood of a country and to show its identity to the whole world. This is very important in revisiting the past and be given tribute to. The paper analyzed the paintings of the different artists of SiningSaysay using the semiology of Ronald Barthes. SiningSaysay: Philippine History in Art is a collaboration project of the University of the Philippines, University of the Philippines Alumnae Association, and the Araneta Center. The twenty-nine (29) paintings can be viewed at the Gateway Gallery in Araneta City showcasing the various crucial chronicle historical events in the Philippines. The Signs in the main material icons of the masterpieces of SiningSaysay had been studied upon as well as the hidden discourses behind those Signs. Through the paintings, it had been found out how the artists used their masterpieces in the formation of Philippine nationhood.

Keywords: sign; icon; siningsaysay; nationhood; history art 


\section{Ang senyas: Diskurso ng pagkabansa mula sa mga pangunahing materyal na icon sa 29 na mga obra ng siningsaysay}

\section{Introduksyon}

Inilahad ng sining ang kasaysayan. Naalala ang kasaysayan sa pamamagitan ng sining saysay. Napanatili ang memorya nito at nabigyang pugay dahil sa sining. Sa paggunita sa nakaraan, depende sa perspektiba ng isang tao, maaaring maging kaibigan o kaaway ang alaala. Kaya mahalaga ang pagiging obhetibo sa sining saysay.

Kung babalikan ang nakaraan, mula Neo-Classic hanggang sa kontemporaryong panahon, punong-puno ang kasaysayan ng napakaraming historikal na painting ng mga nangungunang pintor ng akademikong sining ng Europeo (Defeo, 2015). Noong panahon ng 'halcyon' pinakamatayog na anyo ng sining ang sining saysay. Naging pormal na kaugalian noon na bago mabigyan ng digri o parangal ang isang artist, kailangan muna niyang ipakita ang kanyang tatlong historikal na painting sa akademya (Defeo, 2015).

Sumibol ang matayog na pagpapahalaga para sa sining saysay dahil sa kakayahan nitong magbigay ng malalim na damdaming makabansa, kung gagamitin itong makapagturo sa paraang moral at intelektuwal. Responsibilidad ng isang artist na maikintal ang pambansang kasarinlan (national pride) at maipakilala ang pagkakakilanlan ng isang bayan at lahi nito. Sa pamamagitan ito ng mga kaganapang maipapakita ng artist sa kanyang mga obra na magdiriwang ng pambansang pagkakaisa, katapangan at kabayanihan. Ito ang tinatawag sa akademya na isang painting ala grande maniere.

Isang nang matagal na tradisyon sa UP College of Fine Arts, ang History Art-painting man o iskultura. Nanumbalik ang tradisyong ito noong panahon kung kailan ang Escuela Superior de Pintura, Escultura y Grabado, ang hinalinhan ng kolehiyo (sa panahon ng 1800s) ay nag-atas na kailangang magpasa ng dalawa o tatlong mga likhang sining ang mga estudyante bago sila makapagradweyt. Sinunod ito mula sa academia ng Espanya. Itinatag ang tradisyong ito bilang pagkilala sa kahalagahan ng History Art sa pagpapalaganap ng pagkamakabansa sa mga tao (Defeo, 2015). Kaya hindi maipagkakaila na napakahalaga ng History Art sa pagbuo ng pagkabansa ng anumang bansa. Dagdag pa ni Pascual (2015), "SiningSaysay is an innovative way of teaching and learning history, promoting art, fostering national identity."

Galing sa Sining (Art) at Kasaysayan (History) ang SiningSaysay. Hinuli nito ang espiritu ng History Art, sa engrandeng istilo nito. Pinapalakas ang History Art sa kontemporaryong pagtingin sa paglalahad ng naratibo sa pamamagitan ng iba't ibang boses (polyphonic voices) ng mga nangungunang artist ng UP (Alfonso, 2015). Nagsasalita ang mga artist sa pamamagitan ng mga nalikha nilang biswal na imahe.

Mula sa kolaborasyon ng tatlong institusyon ang SiningSaysay: ang University of the Philippines, UP Alumni Association at ang Araneta Center, Inc. Nagkaroon ng ideya noong 2009 si Carlos Castro, isang retirong propesor sa UPCFA at ibinahagi kay Gari Tiongco-UP regent, tungkol sa paggawa ng koleksyon ng mga malalaking format canvas na painting na maglalarawan ng mga kabayanihang pakikibaka na nakatala sa kasaysayan ng Pilipinas. Humingi ng tulong si Carlos kay Tiongco upang pukawin ang interes ni Jorge Leon Araneta na mabuo ang proyekto. Tinalakay ang paksa kasama ang koponan ng mga curator ng sentenaryo na exhibit. Sa kanilang talakayan nabuo ang pinalawak na ideya ng SiningSaysay (Defeo, 2015).

May dalawampu't siyam (29) na painting sa exhibit sa Gateway Gallery. Nagkukwento ang SiningSaysay tungkol sa Pilipinas sa pamamagitan ng mga painting na may lapad na labing dalawa (12) at may taas na anim (6) na talampakan. "This project is the first of its kind with such great scale and magnitude, Alfonso (2015)." Magiging daan ang malaking proyektong ito sa patuloy na diskurso ng mga mahahalagang pangyayari sa nakaraan. 
Senyas: Diskurso ng pagkabansa mula sa pangunahing materyal icon sa 29 na mga obra siningsaysay

Nagkukuwento tungkol sa Pilipinas ang mga painting. Sinimulan ang naratibo sa sinaunang panahon hanggang sa Ikatlong Republika at ang magkakasunod na mga pangulo. May mga pampakay (thematic) na painting ang ikinalat sa mga sunod-sunod na mga painting.

Nilikha ang mga painting sa pamamagitan ng piling pangkat ng dalawampu't pitong (27) tinitingalang mga UP Alumni artist ng Fine Arts. Ang mga obra ay bunga ng kanilang damdamin. Hindi lamang lahat ay nakabase sa pangyayari, opinyon ng awtor at ibang mga mapagkukunan (sources) kundi pati na rin sa damdamin ng awtor. Sabi ni Defeo (2015)), "An artist holds the act of painting as sacred. It is the supreme moment when he or she is both an angel and a monster: angel when (s)he is inspired to construct and monster when (s)he is enraged to destruct." Mayroon silang sariling mundo habang sila ay nagpipinta dahil sa lalim ng kanilang maaaring pagkukuhaan ng inspirasyon—sa lalim ng kanilang kaluluwa. Natutunan ng mga artist na sa pagdokumento ng kasaysayan, hindi nila puwedeng bawasan ang sanaysay sa pamamagitan ng pagtanggal ng mga mahahalagang bahagi at materyal sa paglalahad ng isang kaganapan. Kailangan nilang maging tapat doon sa espiritu ng naratibo at dapat wala silang baguhin, kahit na mga maliliit na detalye gaya ng paglalagay ng kasuotan at sandata ay kailangang tama ang pagkagawa (Defeo, 2015). Kailangan ito sapagkat tunay na batayan ang pinag-uusapan at hindi bunga o kathang-isip lamang. Nakipag-ugnayan ang mga artist sa mga akademikong diskurso ng mga eksperto, pumili ng panahon sa kasaysayan/temang gawing proyekto, pero kinailangan nilang gumawa muna ng inisyal na mga itim at puting guhit base sa kanilang pangunahing biswal na pananaliksik. Para silang mga historyador. Pagkatapos sinuri ang napakalaking arkibal at pangunahing datos na napili mula sa mga aklatan at internet, gumuhit sila at binago ang biswal na mga datos. May pagdokumento ng mga gawa nila sa pagbibisita sa studio habang sila ay nagpipinta. Ito ang pinakamalaking bahagi ng malikhaing proseso ng SiningSaysay. Ginambala ang pribadong lugar ng mga artist kaharap ang personal na pagbunyag ng kanilang artistikong likha (Defeo, 2015). Binigyan sila ng mga materyales na kailanganin nila ng mga isponsor ayon sa saysay ni Carlos sa mananaliksik.

Magiging daan ang SiningSaysay: Philippine History in Art para sa mga usaping kultural at patuloy na diskurso tungkol sa kasaysayan. Dinala ang sining malapit sa tao at publiko upang mabigyang kahulugan at mapahusay ang kalidad nito. Kung ang isang sining ay makapag-imbita ng madla na mag-isip nang malalim tungkol sa lakas at kahinaan nito, isang pampublikong diskurso ang maaaring sumunod. Daluyan ito upang makahimok ng aksyon. Isang matayog na tungkulin ng sining ay nakapagtuturo ito sa-intelektwal, moral at espiritwal na paraan upang mapabuti ang isip at karakter ng tao, samakatuwid may kakayahan itong magsulid ng kaalaman, magganyak ng kritikal na pag-iisip at magpalakas ng pagkatao ng isang nilalang o kuwento ng tao at ang pinakamatayog — ang kuwento ng buong sangkatauhan.

Ayon kay Gari Tiongco, “...Maging mapang-akit ang konsepto sa mga estudyante upang matuto sa kasaysayan ng Pilipinas na mangyayari lamang sa kalahating araw na pag-ikot at hindi lang basta paglibot sa isang museum kundi inilahad ito sa pamamagitan ng art exhibit...” (Lacuata, 2015). Kung titingnan ito nang malapitan, makikita ang mga detalye at lalong maintindihan ang kasaysayan na maaaring magdagdag sa mga dati ng kaalaman. Isang milyahe talaga sa bansa ang pagkaroon ng mga ganitong exhibit.

Napapaloob sa mga painting ang mga Senyas na nagpapahiwatig ng mga katangiang higit na magpapakilala sa mga Pilipino—nagbibigay ng tiyak na depinisyon sa pagka-Pilipino at pagkabansa ng Pilipinas.

Mahalaga ang mga usaping ito para sa akademya at lipunan. Biniyayaan ang bansa ng maraming mga artist na magdala ng inspirasyon dahil sa ganitong paraan mapag-usapan, mapuna, mabigyang-halaga, makapagbigay alam at higit sa lahat makapaghubog ng damdaming makabansa. Ayon kay Pascual (2015), "Ang SiningSaysay: Philippine History in Art ang aming kontribusyon sa kultural na dayalogo ng Pilipinas na kung saan ang UP ang nagtataguyod at nagpayaman."

\subsection{Paglalahad ng suliranin}

Pangkalahatang suliranin sa pag-aaral: 
$>\quad$ Paano ginamit ng mga artist ang kanilang obra upang mahubog ang pagkabansa ng Pilipinas?

Mga tiyak na suliranin:

$>\quad$ Ano ang mga pangunahing materyal na icon?

$>\quad$ Ano ang interpretasyon o kahulugan ng mga materyal na icon sa mga piling obra ng SiningSaysay gamit ang Senyas (Sign) ni Barthes?

$>\quad$ Ano ang relasyon ng mga Senyas (Sign) sa mga piling obra ng SiningSaysay sa pagkabansa ng Pilipinas?

Tiningnan din kung ano ang mga naging karanasan ng mananaliksik sa mga obra ng pintor.

\section{Balangkas ng teoritikal}

Ang sining ay nagpapaganda ng mundo maliban sa pagbibigay nito ng kasiyahan at kaluguran sa buhay. Maaari rin itong daan sa pagpapahayag ng katotohanan at paniniwala. Mahalaga ang sining sa pagtingin ng paniniwala ng isang tao kaakibat ang pagsaalang-alang ng persepsyon ng artist sa katotohanan. May kakayahan itong dalhin ang isang nilalang sa ibang panahon at dimensyon. Makamit din ang sariling historikal na perspektibo at pag-unawa dahil sa sining at hindi lang iyon kundi pati ang pagpapahalaga ng bawat kuwento ng kasaysayan. Dagdag pa, ang sining ay nakikipagdayalogo sa anumang kultura at nagkukuwento ng nakaraan at ang hinaharap.

May mga artist na naniniwalang ang kanilang mga obra ay may kabuluhan at hindi nasasayang ang oras at pera ng mga tagapanood. Maaaring totoo ito at maaari ring hindi. Ang mga eksperto ay gumagamit ng tatlong teorya upang malaman ang kabuluhan ng mga sining. Ito ay ang mga teoryang pormal, kontekstwal at ekspresib. Mas nakatuon ang pananaliksik sa teoryang kontekstwal. Tiningan ang konteksto ng mundo kung saan ang SiningSaysay ay nabuo. Pinahalagahan din ang iba’t ibang tema nito.

Ang teoritikal na batayan talaga na ginamit sa pagsuri ng mga pangunahing materyal na icon ng dalawamput siyam (29) na painting ay ang semiolohiya ng kritiko at pilosopong si Roland Barthes (1915-1980). Ang semiolohiyang gagamitin sa pag-aaral na ito ay ang semiolohiyang nakapaloob sa kanyang librong Mythologies. Ang mga koleksyon ng sanaysay sa "Myth Today" ay sumuri sa ilang kulturang popular at ang pakay ni Barthes na maipakita ang nakakubling diskurso sa likod ng mga naturang icon.

Ang proyekto ni Barthes sa pagsusuri sa mga nakatagong diskurso sa mga kultural na icon, mga imahe, at mga litrato ay matatagpuan sa mga saloobin ng tatlong dakilang tao sa modernong pilosopiya sa kanluran: Sina Karl Marx (1818-1853), Ferdinand de Saussure (1857-1913), at Sigmund Freud (1856-1939) (Barthes, 1972, sariling salin). Naniwala si Marx na ang mga elementong kultura lalung-lalo na yaong namimighani at nagpapaamo ng mga tao gaya ng sining, literatura, at relihiyon ay nariyan upang takpan ang mga malalalim na mga kontradiksyong nalikha na dating nang lumitaw sa sistemang kapitalista. Nagbigay ang Marxistang pananaw na ito ng inspirasyon kay Barthes upang mailantad ang mga nakatagong diskurso sa likod ng mga icon ng popular na kultura. Sa kabilang dako naman nakumbinsi si Saussure sa isang pangangailangang magtatag ng siyensyang tumutugon doon sa senyas na tinawag niyang "semiolohiya" (Barthes, 1972, sariling salin). Siya din ang nag-isip ng istrukturang senyas na binubuo ng "signifier" o biswal na imahe at ang "signified" o ang mental na imahe (Barthes, 1972, sariling salin). Mula kay Freud, nahinuha ni Barthes ang kaisipang ang semiolohiya ay hindi naiiba sa pagpapakahulugan ng mga panaginip sapagkat isang proseso din sa pagsasalaysay ng mga di-malay na mga diskurso na nakatago sa likod ng mga popular na kultura ang semiolohiya.

Tulad ng nabanggit na, inilaan ni Barthes ang pagdalumat sa senyas na nilikha ni Ferdinand Saussure bilang nabuong signifier at signified:

92 Consortia Academia Publishing (A partner of Network of Professional Researchers and Educators) 


\begin{tabular}{|c|r|}
\hline (1) Signifier & (2) Signified \\
\hline \multicolumn{2}{|c|}{ (3) Senyas } \\
\hline
\end{tabular}

Pigura 1. Ang Senyas ayon kay Saussure

Ginamit ni Barthes ang Saussurian na konstruksyong ito upang gawin ang kanyang unang antas sa pagbuo ng isang ideya na tinukoy niyang antas ng lenggwahe. Mga caption na marginal naman at mga label ang mga suporta nito, at isiningit ang mga ito sa natural na disposisyon ng eksena-- 'en bayme.' Sa kanyang sanaysay na "Rhetoric of the Image," "denotasyon" ang lingguwistikang mensahe sa imahe (Barthes, 1977, sariling salin). Dahil ang semiolohiya ni Barthes ay mas malalim pa kaysa semiolohiya ni Saussure, nagsilbi lang ang Sausssurian na dalumat bilang hakbangan para sa pagbibigay ng konsepto ni Barthes ng Mito (Barthes, 1972, sariling salin). Para kay Barthes walang kinalaman ang Mito sa mga sinaunang alamat, sa halip ang paggamit niya sa salita ay mas malapit sa mga "kontemporaryong paniniwala" o mga "kaalamang" walang matatag na basehan o pundasyon. Ang Mito ay mga diskursong parehong nakikita at nakatago sa likod ng mga icon sa isang lipunan lalung-lalo na sa mga icon ng popular na kultura.

\begin{tabular}{|c|c|c|}
\hline (1) Signifier & (2) Signified & \\
\hline \multicolumn{2}{|c|}{ (3) Senyas } & \multirow{2}{*}{ (5) SIGNIFIED } \\
\hline \multicolumn{2}{|c|}{ (4) SIGNIFIER } & \\
\hline \multicolumn{3}{|c|}{ (6) SENYAS } \\
\hline
\end{tabular}

Pigura 2. Ang Mito bilang mas Malalim na Senyas ayon kay Barthes

Ang Pigura 2 ay nagpapakita kung paano siya gumawa mula sa Sausurre na konstruksyon ng isa pang konstruksyon para maisip ang Barthesian na Mitong ito. Kung titingnan ang figura, ang Saussurian na senyas (numero 3 sa pigura 2) sa antas ng lenggwahe, ay tumayo bilang signifier (numero 4 sa pigura 2) sa antas ng Barthesian na Mito, o sa antas ng signification. Kaya ang Mythology ay tumutukoy doon sa iminungkahing sistema ni Barthes kung paano haharapin ang mga kontemporaryong Mito na ito. Kaya sa "Rhetoric of the Image," ang mensaheng nabubuo sa mga icon ng mga popular na kultura ay pang-konotasyon (connotational) (Barthes, 1977, sariling salin).

Sa dahilang ang "signifier," "signified," at "senyas" o "sign" ay pangalawang ginamit sa Barthesiang dalumat na Mito, napag-isipan ni Barthes na bigyan sila ng mas teknikal na termino. Kaya ang signified ng numerong 2 sa pigura 2 at ang numerong 5 sa pigura 2 ay parehong pinangalanan ng "konsepto"; at ang signifier ng numerong 4 sa pigura 2 ay pinangalanan ulit ng "kahulugan" sapagkat iyan ang panghuli sa elementong Saussuriang dalumat, at ganoon din "anyo" sa dahilang iyan ang simulang elemento sa malalimang konstruksyong Mito; at ang senyas ng numero 6 sa pigura 2 ay pinangalanan ulit ng "signification" (Sinipi ni Demeterio, 2013 kay Barthes, 1972, sariling salin). Makikita ito sa Pigura 3:

\begin{tabular}{|c|c|}
\hline (1) Signifier & $\begin{array}{c}\text { (2) Signified } \\
\text { (Konsepto) }\end{array}$ \\
\hline \multicolumn{2}{|c|}{ (3) Senyas } \\
$\begin{array}{c}\text { (4) SIGNIFIER } \\
\text { (Kahulugan/Anyo) }\end{array}$ & $\begin{array}{c}\text { (5) SIGNIFIED } \\
\text { (Konsepto) }\end{array}$ \\
\hline \multicolumn{2}{|c|}{ (6) SENYAS (Signification) } \\
\hline
\end{tabular}

Pigura 3. Mas Epektibong Pagpapahayag ng Dalumatng Mito ayon kay Barthes

Sa pamamagitan nitong mas epektibong konstruksyong Mito, mas malinaw na naipakita ni Barthes ang 
komplikadong katangian ng signifier (numero 4 sa mga pigura 2 at 3) na nagsasaad bilang kahulugan kung Saussuriang dalumat na senyas ang pag-uusapan, at bilang anyo kung ang Barthesiang dalumat na Mito naman ang pag-uusapan. Ayon kay Barthes, ang pagtatayon (oscillation) ng signifier (numero 4 sa mga pigura 2 at 3) sa pagitan ng kahulugan at anyo, o sa pagitan ng puno at walang laman, magiging bukas sa posibilidad na mapupunan pa ito ng mas malalim na signified (numero 5 sa pigura 2 at 3) upang lumikha ng prosesong panibagong senyas (numero 6 sa pigura 2 at 3), o signification o Mito. Ang konotasyon at Mito ay hindi talagang parehong-pareho. Ang Mito ay sadyang inilagay sa grupo ng mga ahente sa ilalim ng kultural na icon (Sinipi ni Demeterio, 2013 kay Barthes, 1972, sariling salin).

Para sa pananaliksik na ito, ang midyum ng sining na sinuri ay ang Fine Art—mga larawan mula sa obra ng SiningSaysay. Layunin din na tatalakayin ang mga piling larawan gamit ang semiolohiya ni Barthes dahil mas nakaangkla ang pagsusuri sa mga Senyas. Ang inisyal na semiotic na pagtingin ay nagpapatuloy upang abuksan ang mas marami pang mga kompleks na posibilidad kasali na ang pagtukoy sa iba't ibang mga antas o 'orders' ng signipikasyon at ang konsepto ng Mito.

\section{Kaugnay na pag-aaral at literatura}

Gaya ng SiningSaysay, nagsimula din sa isang 'ideya' ang EL PRADO PROJECT: Dialogue with the Masters na isang pagpapakahulugan ng mga painting ng Museo Nacional del Prado sa Ayala. Plano ito ng isang artist na magtipon ng isang koleksyon na mga obra ng mga artist kasali ang kanyang mga gawa, "kung papaano sila tutugon, muling magpapakahulugan, magpapakita, gagawa, manggagaya, mangongopya o simpleng inspirasyon lamang" mula sa mga piling artwork ng mga piling Spanish master na nakasabit sa Museo Nacional del Prado sa Madrid Spain. Magsisilbing isang malakas na malikhaing catalyst ang painting upang makarating doon sa iba namang antas ng masining na obra mula sa kapwa namang artist na galing sa ibang dimensyon ng panahon. Sa pamimilosopiyang katotohanang ito, ang pagpapakahulugan ng orihinal na artist sa kanyang biswal na representasyon ng medyum ay muling maipakita sa ibang artist sa kasalukuyang panahon. Gaya ng sinabi ng Amerikanong artist na si Robert Rauschenberg, "I don't think there is anything really wrong with influence because I think that one can use another man's art as a material either literally or just implying that they are doing that, without it representing a lack of point of view." Ito marahil ang pangunahing dahilan kung bakit sa pangkalahatan ang sining ay nananatiling buhay, makulay at walang katapusan (Esguerra, 2010). May malaking impluwensya din talaga ang SiningSaysay exhibit sa lahat pati na rin sa iba pang mga artist. Kaya sinong makapagsabi na balang araw ay dadami ang mga art exhibit/art institution hindi lamang sa Kamaynilaan kundi pati na rin sa ibang panig ng Pilipinas.

Ito naman ang karanasan ng bumuo ng EL PRADO PROJECT: Dialogue with the Masters: "Exhibitions like these never take place without teamwork and cooperation, which make all conversations possible. We are primarily grateful to the Embassy of Spain led by His Excellency Luis Arias and his supportive staff having partnered with the Ayala Museum for this extraordinary collaboration... We are also grateful to the Museo Nacional del Prado for participating in this exhibition using images of the masterpieces in their collection. ... grateful to the artists, whose bold expressions and re-interpretations of the master for a stimulating and profound dialogue" (Luz, 2010).

Ayon naman kay Smith (2015): "Of all ideological movements, nationalism is most closely associated with artists, especially visual artists..." Nauugnay kalimitan ang mga aritst sa mga konseptong nasyonalismo at pagkabansa dahil lahat sila ay may pinanggalingan at pinagmulan. May koneksyon ang mga gawang sining sa pagkabansa. Ayon kay Matos (12), "All real art is national simply because international art cannot exist since there is no international artistic expression: an expression that would be understandable to the same degree to all nations around the world and that would not have a national genesis."

Nagbibigay ng iba't ibang perspektibo ang mga painting at sining sa pagkalahatan. Para itong 'snapshot' ng kasaysayan at ng anthropolohiya. Nagdadala ito sa iba't ibang konsteksto ng lipunan na may natatanging kultura.

94 Consortia Academia Publishing (A partner of Network of Professional Researchers and Educators) 
Senyas: Diskurso ng pagkabansa mula sa pangunahing materyal icon sa 29 na mga obra siningsaysay

Dahil sa mga painting mas lalong naintindihan ang isang kultura. May koneksyon ang isang gawang sining at kultura (Howells at Neigreros, 2012) sabi nila, "Geertz was like us, concerned with culture, and the way which our cultural values and concerns are articulated in symbolic texts." Isa pa, upang maunawaan ang kultura kailangan ding unawain ang mga tao, kaya simulang isiping mabuti na isa sa pangunahing benepisyo ng pagsusuring biswal na kultura: maitindihan ang sarili. Hindi naman mahihirapan ang isang indibidwal na unawain ang sining sapagkat ayon kina Laugée at Rabiller (2020) “... It is indeed easier to address and judge the artistic production corresponding to one's own culture, since in this case the critic is supposed to perfectly master the artistic, historical, cultural and sociological context of the work." Kaya mas mahirap talagang tingnan at suriin ang sining sa ibang bansa sapagkat kalimitan ay hindi alam ang kultura, relihiyon at pulitika na maaaring magdulot ng maling paghatol sa kanilang mga obra.

Ayon kay Laugée at Rabiller (2020), "The accumulation of discourses on art-whether they come from a government, critic, or art historian-form a whole that is difficult to grasp, one which expresses a nation's collective view of its artistic production... These writings on "schools" are subject to geography and politics, and therefore any definition of this type is a shifting one. It is valid only for a period or a given social context and emerges only thanks to a doctrine that is common to a group of individuals." Dagdag pa nito, ang mga institusyon ng sining na tinaguriang "pambansa" ay mga bagay na napakakumplikado na kung saan ang mga kasaysayan ay maaaring maikuwento sa maraming paraan pero kailangan pa ring maging obhetibo kung kasaysayan ang pag-uusapan. Isa pa, "Discourse on art proved to be nationalist, in the sense that it measured artists as much as it compared the state of various national schools. Thus, through an individual judgment on a country's production, the art critic and historian together form a politics of viewing art ayon kay Laugée at Rabiller (2020). Ang sining ay maaaring maintindihan bilang isang anyo o nagbibigay ng konrtibusyon bilang isang pulitikal na diskurso - deskriptibo, interpretatibo o tasahang kritikal na diskurso. Ang mga usaping pansining din ay mga usaping pambansa batay sa mga iba't ibang pilisopiya o depende na rin sa pagtingin ng isang kritiko.

\section{Metodolohiya}

Sa pag-aaral na ito, ang materyal sa pagsusuri ay ang dalawampu't siyam (29) na mga painting ng SiningSaysay na mga obra ng dalawampu't pitong (27) artist ng UP College of Fine Arts na matatagpuan sa Gateway Gallery, ang art museum ng Araneta City na nagpopromote ng sining. Itinatampok sa exhibit hindi lang ang sining kundi pati na rin ang kultura at kasaysayan ng Pilipinas. Ang inaugural na exhibit, SiningSaysay: Philippine History in Art ay isang landmark na proyekto na nagpapakita ng dalawampu't siyam (29) na malalaking painting ng kasaysayan ng Pilipinas na isang proyekto ng University of the Philippines, ang UP Alumni Association at Araneta City.

Ang pagkakaayos ng mga painting na sinuri ay ayon sa pinaka-paulit-ulit hanggang sa hindi (most recuurent to the least recurrent) ng mga pangunahing materyal na icon ng dalawampu't siyam (29) na mga painting. Sa pananaliksik na ito, dahil sa sobrang dami ng mga materyal na icon na makikita sa bawat painting, pinili lamang ang pangunahing materyal na icon sa mga painting. Sinuri ang mga ito gamit ang semiolohiya ni Barthes.

\subsection{Disenyo ng pananaliksik}

Ang pag-aaral ay diskriptiv dahil sinusuri ang mga gawa ng sining, ano ang mahinuha na mga diskurso mula sa mga painting at ano ang magiging karanasan ng mananaliksik sa mga obra ng mga pintor. May tungkulin ding ginampanan ang paradigm na ito.

Gumagamit din ang pag-aaral ng kontekstwal na pagsusuri at nailalagay ang sining sa kung anong konteksto ito tumutukoy. Sinusuri din kung ano ang ipinapamalas ng sining sa panahon kung saan ito tumutukoy at base din sa perspektibo ng artist. 


\section{Ang pagsusuri sa mga materyal na icon ng mga painting}

Ang kasunod na Pigura ay nagtala sa mga painting at ang mga pangunahing materyal na icon ng mga ito na mismo ang mga Signifier at ang mga Signified. Tatalakayin naman ang mga Senyas sa mga mga kasunod na mga talata.

\section{Talahanayan 1}

Matrix ng mga painting at pangunahing materyal na icon: Ang signified at signifier

\begin{tabular}{|c|c|c|}
\hline Painting & Signifier & Signified \\
\hline March of Labor in the Philippines & mga lalaking nagmamartsa & Manggagawa sa Pilipinas \\
\hline Dyipni Ride & 2 lalaking nakasakay sa dyip & Pres. Ramos at Estrada \\
\hline Re-asserting Independence & lalaking nakasakay sa kabayo & Gregorio del Pilar \\
\hline Babae & babaeng nakasakay sa kabayo & Gabriela Silang \\
\hline American Betrayal of an Ally & lalaking nakaupo sa silya & Macario Sakay \\
\hline The Philippines under the Stars \& Stripes & babaeng nakatayo-hawak 2 bandila & Komonwelt; boto (babae) \\
\hline Yellow Fever & lalaking nakadilaw - sign $\mathrm{L}$ & dilaw-protesta at L-Laban \\
\hline & isang babaeng nakadilaw & Pres. Cory Aquino \\
\hline Reunion & isang lalaking nakatayo & Jose Rizal \\
\hline Pre-Hispanic Philippines & lalaking nakaupo sa gilid & Datu sa Pilipinas \\
\hline Breaking Colonial Ties & apat na mukha ng lalaki & Rizal, Jaena, del Pilar, Bonifacio \\
\hline Post-War Philippines & tatlong mukha ng lalaki & Magsaysay, Garcia at Macapagal \\
\hline Quezon and Osmeña Administration & dalawang mukha ng lalaki & Pres. Quezon \\
\hline Quirino Presidency & isang mukha ng lalaki & Pres. Quirino \\
\hline The Onset of the Revolution & mga watawat & Mga Makasaysayang Watawat \\
\hline Building from the Ashes & dalawang watawat & Watawat ng Pilipinas at Amerika \\
\hline The Filipino Struggle for & watawat & Watawat ng Pilipinas \\
\hline \multicolumn{3}{|l|}{ Philippine Independence } \\
\hline Occupied Philippines & golpo & Labanang Amerikano at Hapon \\
\hline The Battle of Mactan \& Christianization & dagat & Tabing-dagat ng Mactan \\
\hline Pambansang Bangka & bangka & Pambansang Bangka ng Pilipinas \\
\hline Galleon Trade & malaking barko & Barkong Galyon \\
\hline Pre-Historic Material Culture & banga & Banga ng Manunggul \\
\hline Angono Petroglyphs & $\begin{array}{l}\text { incision ng linya, guhit, pigura, } \\
\text { tatsulok, bilog }\end{array}$ & Petroglyphs ng Angono \\
\hline The Ghosts of the Future & Pintados & Mga Bisaya \\
\hline The West Discovers the Philippines & krus, espada at korona & Instrumento ng pasipikasyon \\
\hline The Sarimanok as Cultural Symbol & manok & Mythical Sarimanok \\
\hline Tatak Pinoy & bahay & Pilipinong bahay-kubo \\
\hline The Journey Continues & mekanikal na gulong & Siyensiya at Teknolohiya \\
\hline Batas Militar & pahayagan & Marcos-Martial Law \\
\hline Celebration & imahen & Senyor Santo Niño \\
\hline
\end{tabular}

Ang mga sumusunod ay ang mga painting ng SiningSaysay:

\subsection{March of labor in the Philippines}

Ang pintor sa likod ng painting na ito ay si Neil Doloricon.

Ang Senyas ay ang kalagayan ng manggagawang Pilipino.

Ang punto talaga ng artist ay hindi pagbigay-galang sa mga pinuno ng paggawa (labor) dahil maraming mga isyu sa paggawa. Ang mga nagmamartsa sa painting ang pagtuunan ng pansin. Ang pagmartsa tungo sa pagpapabuti ng mga grupo ng manggagawa at magsasaka ay ang layunin nina Jacninto Manahan, lider ng Confederacion de Apaceros y Obreros Agricolas de Filipinas; ni Crisanto Evangelista, tagapagtatag ng Katipunan ng mga Anakpawis ng; ni Pedro Abad Santos, tagapagtatag ng Socialist Party at ng Aguman Ding Maldang Talapagobra; at ni Manahan at Evangelista, tagapagtatag ng Partido Komunista ng Pilipinas. Hindi lamang sila kundi marami pang mga lider na manggagawa na hangad lamang ang kapanan ng lahat. Ang lahat ng mangagawang Pilipino ay dapat harapin ang mga hamon sa makabagong panahon. Ayon kay Doloricon (2015), "Pinapakita 'yung pagpapanday ng manggagawa sa kanilang kinabukasan... hindi lamang simpleng patungo sa kung ano mang lipunan kundi sa isang modernong lipunan na tinatahak ng manggagawa.” Ang mga ordinaryong mamamayan ay nagkaisa upang ipahayag ang kanilang pangarap at hinaing. Ang unyonismo ng kalakalan ay ang pangunahing kilusan ng paggawa sa mundo ng kapitalismo. Kailangan talaga ito. Ang nag-iisang manggagawa 
Senyas: Diskurso ng pagkabansa mula sa pangunahing materyal icon sa 29 na mga obra siningsaysay

ay walang kapangyarihan laban sa kapitalistang amo kaya upang maayos ang sagabal na ito, mayroong mga unyon na bumibigkis sa mga manggagawa na iparating ang kanilang mga hinaing.

Sa pamamagitan ng painting nahubog ang pagkabansa ng Pilipinas dahil nagkaisa ang mga mamamayan at inaasam ang kapakanan ng kapwa manggagawa at sa buong sambayanan upang mapaayos at mapabuti ang kanilang samahan tungo sa magandang kinabukasan. Nagkaroon ng damdaming makabansa sapagkat tiningnan hindi lang ang sariling interes kundi ng karamihan at ang pagnanasang makatulong.

\subsection{Dyipni ride}

\section{Ang pintor ng painting na ito ay si Michael Velasco.}

Ang Senyas ay ang mga kontribusyon ng mga presidente. Sa pamumuno ni Presidente Ramos nagkaroon ng paglago ng ekonomiya, demokratikong pagsasama-sama (consolidation), pagtatag ng sistema ng pampulitika, pagwakas ng mga kudeta na nagpahirap sa bansa noong dekada 80 at marami pang iba. Nagawa niyang patatagin ang barko-ang Pilipinas tungo sa pangitain niyang "Philippines 2000" na maging tiger economy ang bansa. Nanaig naman ang kapayapaan sa bansa noong pinalawak niya ang amnestiya sa mga miyembro ng Reformed Armed Forces (RAM); nakipagnegosasyon siya sa Moro National Liberation Front (MILF) para maibsan ang hidwaan sa pagitan nila at ng gobyerno at ginawa niyang Tagapangulo ng Southern Philippines Council for Peace and Development (SPCPD) at sa National Democratic Front (NDF) si Nur Misuari. Gusto ni Ramos na maging Newly Industrialized Country (NIC) ang bansa. Sa Development Diplomacy ni Ramos, itinaguyod ito upang makakuha ng mga bagong merkado, makaakit ng maraming kapitalista pati mga turista.

Habang si Presidente Estrada naman ay iprinoklama bilang Senternayong Pangulo at namuno sa mga pagdiriwang sa pagmarka ng sentenyal na deklarasyon ng Kalayaan. Ginamit niya ang sikat na "Jeep ni Erap" sa kanyang kampanyang "justice, economy, environment and peace” o JEEP. Nang tumakbo sa pagkapangulo, ginamit niya ang slogan na "King of the Road" upang ipakita ang imaheng maka-mahirap. Meron din siyang episode sa radio-TV na programa, JEEP ni Erap: Ang Pasada ng Pangulo. Isang sikat na artista si Erap bago naging pangulo noong 1998. Ngunit noong Oktubre 2000, ibinunyag ni Luis Singson na tumanggap ang pangulo ng milyon-milyong suhol sa huweteng at buwis sa tabako. Kumalat noon ang mga anomalya. Naipasa ang kasong impeachment laban sa kaniya. Gumulo ang paglitis at nauwi sa People Power. Ito ang EDSA Dos at nagpatalsik kay Erap. Nabilanggo siya ngunit nabigyan ng pardon.

Ang mga pangulo ay may papel at tungkulin para sa kapakanan ng mga taumbayan. "The goal of nation-building is to build the collective capacity to achieve public results and to pursue a shared vision of the future," Bourgon (2010). Totoo na ang pangkolektibong kakayahan upang makamit ang inaasam para sa bayan ay hindi lamang limitado sa gobyerno, kundi pati ang mga tao mismo (people's role in nation building) at sabay harapin ang mga hamon at pagsubok. Mabubuo ang pagka-makabayan kung tutuparin itong lahat. Humuhubog ito sa pagkabansa ng Pilipinas sapagkat ang kapakanan ng mamamayan ang dapat mauna kaysa pansariling interes lamang. Isa pa, ang mga nagawa ng mga nakaraang presidente ay dapat ding masuri upang magkaroon ng kamalayan nang sa ganoon ay hindi na maulit ang maling napagdaanan.

\subsection{Reasserting independence}

Ang pintor sa painting na ito ay si Norman Dreo.

Ang Senyas ang pag-alay ni batang del Pilar sa kanyang buhay.

Tinaguriang 'King of Leonidas of the Philippines' si Gregorio del Pilar — na lumaban sa Digmaang Pilipino-Amerikano, isinilang sa Bulacan, Bulakan noong 14 ng Nobyembre 1875. Sa murang gulang sumapi si del Pilar sa Katipunan.

Inihalintulad siya kay King Leonidas na "The King who died to the last man." Walang kaduda-duda ang 
pagkatalo ng mga Greek. Ang Labanan ng Thermopylae' at tinagurian si King Leonidas at tauhan bilang mga martir na nag-iwan ng pamana na tumagal ng isang milenyo (Ancient Origins, 2019, sariling salin). Napakasikat na kuwento ng katapangan na maihalintulad kay del Pilar ang 'King of Leonidas in the Philippines.' Sinakripisyo ang sarili upang kalabanin ang mga Amerikano sa napakatanyag na 'Labanan sa Paso ng Tirad' o 'Philippine Thermopylae.' Pinadaan niya si Aguinaldo sa paso at hinarap ang mga Amerikano at nakipaglaban upang makatakas si Aguinaldo. Hindi man lang naisip na mas nakalamang ang mga Amerikano kung sandata ang pag-usapan. Nakipaglaban na kasama lamang ang lakas na loob at tapang. Noong namatay na si del Pilar, kinuha ng mga Amerikano ang mga badge sa kanyang uniporme bilang memorabilia sapagkat saludo sila sa katapangan ni del Pilar.

Halos pareho ang "Labanan ng Thermopylae at ng Pasong Tirad." Magkaibang panahon, lugar, at nilalang pero halos pare-pareho ang kuwento ng sakripisyo, katapangan at kabayanihan.

Sa talaarawan ni del Pilar, sinabi niya na napakabigat daw ang ipinagawa sa kanya pero iyon na ang pinakamaluwalhating sandali ng buhay niya at wala nang ibang sakripisyo ang hihigit pa para sa Inang bayan (Almario, 2015).

Ipinapakita ang kabayanihan, katapangan at pakikiisa ni del Pilar sa kapwa niya sundalo. Ang katangiang ito ang nagpapatanyag ng mga Pilipino sa buong mundo—ang pagpakamatay para sa sariling bayan. Humuhubog ang kabayanihan at katapangan sa pagkabansa sapagkat isa itong pagkakakilanlan na tanda ng pagka-Pilipino. Nagkakaroon ng kamalayan sa kung ano at sino ang tunay na Pilipino- hindi lamang sa salita pati na rin sa gawa.

5.4 Babae

\section{Si Grace Javier-Alfonso ang pintor sa painting na ito.}

Ang Senyas ay ang kapangyarihang pangkababaihan.

Si Gabriela Silang ay sagisag ng kapangyarihang pangkababaihan at kahalagahan ng mga kababaihan sa lipunan. Ang kapangyarihang gawin ang mga bagay na gusto nilang gawin na ipinamalas ni Gabriela Silang. Sa pagpapatuloy ng Pilipinas sa landas tungo sa kalayaan noon, nandiyan ang mga babaylan sa sinaunang panahon sa katauhan ni Gabriela Silang na pumalit sa kanyang asawa kanyang pakikikbaka laban sa mga Kastila. Hindi lamang si Gabriela Silang ang nagpapakita ng kanilang tapang at galing sa mga digmaan sa tabi ng mga kalalakihan kundi marami pang iba gaya ni Teresa Magbanua, Melchora Aquino o Tandang Sora, Agueda Kahabagan, Trinidad Perez, kababaihan ng Malolos, mga suffragette na nangampanaya para sa karapatan ng mga Pilipina na makaboto at mga kababaihan ngayon na patuloy na nakikipaglaban para sa mga karapatang pangkababaihan at ganap na implementasyon ng Magna Carta para sa Kababaihan. Talagang nagpapatuloy ang mga kababaihan na makamit muli ang kapangyarihang unti-unti nang naglaho noon. Ang kamalayang ito sa kahalagahan ng mga kababaihan ay isang kontribusyon para sa pagkakaroon ng pagpapahalaga sa sarili at pagka-makabansa sapagkat naniniwala ang mga Pilipino sa kulturang pagkakapantay-pantay ng mga kalalakihan at kababaihan. Importante din na malaman ng mga kabataan ngayon ang nagawa nila sa kasaysayan.

\subsection{American betrayal of an ally}

Si Norman Dreo ang pintor sa painting na ito.

Ang Senyas pag-alay ng buhay at kabayanihan.

Ginawa ng mga Amerikano ang mga Pilipino na maging kaalyado sa digmaang Kastila at Amerikano pero sila na naman ang naging bagong mananakop ng bansa. Kaya nagkaroon ng Digmaang Filipino-Amerikano upang muling ipagtanggol ang bansa sa matagal nitong inaasam-asam na kalayaan. Si Macario Sakay ang isa sa mga tagapagbuo ng Katipunan sa Maynila. Itinatag niya ang mga ibang pangkat ng gerilya sa Timog 
Senyas: Diskurso ng pagkabansa mula sa pangunahing materyal icon sa 29 na mga obra siningsaysay

Katagalugan. Sumuko siya sapagkat nakumbinsi siya sa tulong ni Dominador Gomez na isang pinagkatiwalaan niyang lider na manggagawa noon, na bibigyan sila ng amnestiya. Nangako rin ang mga Amerikano na buuin ang Pambansang Asemblea kung magkaroon ng katahimikan. Nang bumaba si Sakay kasama ang kanyang mga heneral mula sa himpilan sa Tanay, Rizal, sa isang piging sa Cavite ay bigla at pataksil siyang hinuli, ikinulong at dali-daling inilitis. Binitay pa siya noong Setyembre 13, 1907 (Sakay, 2015). Simpleng pag-alay ng kanyang sariling buhay ang kanyang naihandog. Ang kabayanihan at katapangan na naipamalas ay humuhubog ng pagkabansa. Dahil sa katapangan ng mga Pilipino noon naging malaya ang bansa. Iginiit nilang dapat hindi mapasakamay ang Pilipinas sa mga dayuhan sapagkat mawalang saysay ang mga ipinaglaban ng mga naunang rebolusyonaryo.

\subsection{The Philippines under the stars and stripes}

Ang pintor sa painting na ito ay si Cris Cruz.

Ang Senyas ay ang paghangad ng Kalayaan, karapatan ng mga kababaihan at marinig ang kanilang boses.

Noong March 24, 1934, dahil sa probisyon ng Tydings-McDuffie Act, nilagdaan ni Presidente Franklin D. Roosevelt ang Philippine Commonwealth at Independence Act. Masaya na ang mga Pilipino dahil sa wakas magkakaroon na ng Kalayaan ang Pilipinas. Sa 10 taong transisyon ipapatupad ang Pamahalang Komonwelt. Nagkaroon ng eleksyon para sa magiging presidente at nanalo si Quezon at bise presidente naman si Osmeña. Sa panahong iyon, marami ang ipinatupad ng pamahalaang Amerikano at isa na doon ang pagbigay ng karapatang bomoto sa mga kababaihang Pilipino. Noong panahong iyon, isinaad sa isang probisyon ng 1935 na Konstitusyon na ibibigay ang karapatang pagboto ng mga kababaihan kung hindi kukulang ng 300 na mga kababaihan ang boboto na sasang-ayon sa plebisito. Kaya hinimok ng mga iba't ibang organisasyon ng mga kababaihan ang kapwa kababaihan upang dadami ang magparehistro at boboto. Nagkaroon ng multilinggwal na kampanya gamit ang radyo noong gabi bago ang halalan ng mga kababaihang lider gaya nina Judge Natividad Lopez (Spanish), Josefa Martinez (Ilongo), Pilar Lim (English), Concepcion Rodriguez (Tagalog), Geronima Pecson (Pangasinan), Corazon Torres (Cebuano), and Josefa Escoda (Ilocano) (Casambre \& Rood, 2012). 86\% ang talagang bumoto noong Abril 30, 1937. Bumoto ang mga kababaihan noon ng 10 sa 1 (10 to 1) sa affirmative at nanalo sila ng lampas sa kuta ng Konstitusyon. Kaya nakuha nila ang boto. Ito na iyong pag-unlad ng mga kababaihan dahil sa kanilang pagpupunyagi sa unang bahagi ng ika-20 siglo (Casambre \& Rood, 2012). Nagkaisa ang mga Filipina na ipaglaban ang kanilang karapatan at marinig ang kanilang boses nang sa gayun ay magkaroon sila ng kapangyarihang pulitikal (political empowerment). Nagpapatibay ito ng pagkabansa ng Pilipinas sapagkat may pagkakaisa ang mga kababaihan at mapaayos ang kanilang pamumuhay. Hindi lamang ang kanilang buhay kundi pati na rin ng lahat ng mga kababaihan sa Pilipinas.

\subsection{Yellow fever}

\section{Si Angel C. Cacnio ang pintor ng painting na ito.}

Ang Senyas ay ang pagkakaisa ng mga Pilipino.

Tanda ng protesta ang kulay dilaw at ang wikang pang-kamay (hand language) na nagpapahiwatig ng "Laban". Si Cory Aquino ang naging icon o simbolo ng demokrasya sa Pilipinas dahil sa tulong niya sa pagwawakas ng Batas Militar na ipinatupad ni Marcos. Dahil sa Himagsikan ng Lakas ng Bayan, nang nagmartsa ang mga tao sa EDSA, natapos na sa wakas ang mga madilim na araw sa Pilipinas bunsod ng pagsuporta ng mga tao kay Cory Aquino. Nagkaisa sila na tunguhin ang adhikain para sa pagbabago. Tinatayang nasa mahigit dalawang milyong katao ang nakilahok sa protesta. Dahil dito, naibalik ang demokrasya at bumagsak ang pamahalaang diktatoryal. Sabi ni Cacnio (2013) "Natuwa ako nang husto kasi ibig kong makita nila na ang Pilipino ay mayroong magandang adhikain na magkaroon ng magandang pagbabago sa ating bansa." "Magkaisa, magsama, kapit-kamay sa bagong pag asa..." ang kantang ito ay dinig na dinig sa mga radyo noong panahong iyon. Ang pagkakaisa nila ang naging resulta sa matatag na pagkabansa noon. May mga problema ding 
kinakaharap ngayon ang bansa, marami - isa na doon ang kulturang imperyalismo na humahadlang sa pagbuo ng pagkabansa na unti-unting sumisira sa pagpapatuloy ng kasaysayan kaya maaaring mabura ang pagiging pagkabansa ng Pilipinas. Pero dahil sa pagsisikap ng lahat pati na ng pamahalaan, nalampasan ang lahat ng ito at nabuo pa rin ang malakas na damdaming makabansa at ang pagkabansa ng Pilipinas.

\subsection{Reunion}

\section{Si Janice Young ang pintor sa painting na ito.}

Ang Senyas ay pagka-Pilipino ng mga Instik.

Mahaba ang listahan ng angkang Intsik na pinanggalingan ni Rizal na bumubuo din sa lahing Pilipino. Ayon ni Reyno (2012), ang paternal na angkan ni Rizal ay galing sa Siongque sa Chin-Chew na isang distrito ng Fujian, hilagang Tsina. Ilan sa mga talagang nakakilala sa kanyang angkan ay sina Siang-co at Zun-nio na nanganak ng lalaki, si Lam-co na pumunta sa Pilipinas noong huling bahagi ng 1600s. Kaya doon nagmula ang angkan ni Francisco Mercado Rizal na ama ni Jose Rizal at ina niyang si Teodora Alonso Realonda Rizal (Reyno, 2012).

Ang ugnayang Pilipino at Tsino ay matagal nang nagsimula sa Pilipinas, mga ilang daang taon na ang nakalipas bago dumating ang mga Kastila dala ang sari-saring paninda gaya ng porselana, seda, bakal at iba pa. Ang produkto naman ng Pilipinas ay bulak, perlas, banig at iba pa. Barter ang tawag sa sistema ng kalakalan noon. Pagdaan ng panahon ang mga mangangalakal na Tsino ay nagtayo na ng kanilang pamayanan sa mga baybayin sa mga kapuluan at hindi na nakabalik sa Tsina at tuluyang nakapag-asawa sila ng mga babaing katutubo. Dahil dito, nagsimulang mahaluan ng kulturang Tsino ang kulturang Pilipino. Kaya hindi maipagkakaila na may lahing Tsino talaga ang mga Pilipino. Ang tawag sa mga lahi nila ay Chinese mestizo gaya nina Rizal, S. Osmeña, CJ C. Teehankee, Cardinal Sin, C. Aquino at iba pa. Kaya masasabing bahagi sila ng paghubog ng pagkabansa dahil malaki din ang kanilang kontribusyon sa pambansang ekonomiya at lipunan. Sa katunayan maraming mga Tsino ang lumaban at namatay noong laban para sa Kalayaan. Noon din sa panahon ng Kastila, nakadepende ang ekonomiya ng bansa sa kanila. Pinapakita nila ang kanilang pagka-Pilipino at kanilang ugnayan sa mga tunay na Pilipino. Magpahanggang ngayon, malaki ang ambag ng Komunidad ng Instik sa Pilipinas na lalong nagpatatag ng bansa.

\subsection{Pre-hispanic Philippines}

Si Randy Solon ang pintor sa painting na ito.

Ang Senyas ay ang pamumuno ng Datu sa isang balangay.

May kinikilalang lider na tinawag na datu ang organisadong pamumuhay noon ng mga pangkat na mga kamag-anak. Sa lipunang Bisaya tulad ng Panay, Cebu at Leyte, ang datu ang nasa pinakamataas na antas ng nasakop na lipunan. Sila ay sinusunod bilang lider at tinutulungan ng mga timawa o alipin. Naging mahalaga ang mga datu sa pananakop ng mga Español sa Pilipinas at gayundin, sa paghadlang sa kanila. Sa lipunang Muslim, itinatalaga ng Koran ang Sultan bilang pinakamataas na antas sa lipunan at sinusundan ng mga datu.

Tinutukoy ang mga etnikong grupo bilang mga ibinabahaging kulturang pamana, ninuno, mito o pinagmulan, kasaysayan, at wika na mahalaga para sa mga kasapi nito. Ipinapamalas ang mga ito sa sistema ng kanilang pananampalataya, mga pagkain nila, mga ritwal, pananamit at pakikipag-ugnayan sa iba. Sa kanilang uri ng pamumuhay bilang isang organisadong grupo, kinikilala nila ang pamumuno ng isang Datu. Nagpapakita talaga ito ng pagkabansa ng Pilipinas dahil noon pa man bahagi na ang tinatawag na balangay na pinakamaliit na yunit ng lipunan sa pulitikal na aspeto ng Pilipinas na pinamunuan ng isang Datu. Nakilala ang mga Pilipino noon dahil sa mga samahang ito at nagpapatuloy ang sosyo-pulitikong grupo hanggang sa ngayon na sumsalamin sa mga pamumuhay ng tunay na Pilipino. 
Senyas: Diskurso ng pagkabansa mula sa pangunahing materyal icon sa 29 na mga obra siningsaysay

5.10 Breaking colonial ties

Si Romeo G. Mananquil ang artist sa painting na ito.

Ang Senyas ay ang kabayanihan at katalinuhan ng mga apat na bayani.

Si Rizal, Jaena, del Pilar at Bonifacio ang mga protagonist na nakibaka para sa Kalayaan—sa mapayapang paraan at sa pamamagitan ng rebolusyon. Ang kinasasangkutan ng apat na ito sa kasaysayan ng bansa ang pinakamahalaga sapagkat sila iyong nangunguna sa laban upang makamit ang Kalayaan. Nagkaroon ng Kalayaan sa panahon ng Kastila, unang-una dahil sa mga ideolohiya ni Rizal na makamit ang mga ninais na reporma hanggang sa nabuo ang Kilusang Propaganda na aktibo namang nilahukan ng iba pang mga Propagandista tulad ni Jaena na isang napakatanyag na mambibigkas (orator) at si del Pilar na isang political analyst. Sa mapayapang paraan ang kanilang hangarin subalit taliwas naman ito sa ideolohiya ni Bonifacio sapagkat nakatuon sa rebolusyon na para sa kanya ang solusyon sa pagkamit ng Kalayaan.

Kung ano man ang tinatamasa ngayon ng mga Pilipino ay dahil sa kanilang pagpupunyagi kaya ang pagkabansa ng Pilipinas ay mas lalong nahubog dahil sa kanilang pagpursige kahit buhay man ang kapalit. Ang natamong kalayaan ngayon ay dahil din sa kanilang angking galing at talino. Makapagbigay sana ito ng inspirasyon sa mga kabataan ngayon, ang kanilang nagawa para sa bayan.

\subsection{Post-war Philippines}

Ang pintor sa painting na ito ay si Ben F. Infante.

Ang Senyas ay ang mga kontribusyon ng tatlong presidente.

Isa sa pinakamahusay na presidente si Magsaysay pero ang kanyang mga plano ay nanatiling blueprints o plano lamang dahil sa kanyang maagang pagkamatay. Nagustuhan siya ng mga karaniwang tao sa pagbukas niya sa Malacañang Palace. Napabuti din niya ang buhay ng mga tao sa kanayunan sa pagpalit ng sistema ng panunungkulan sa lupa. Noong 11 ng Agosto, 1955, inaprubahan ng Kongreso ang batas na nagbigay kapangyarihan kay Magsaysay na paghati-hatiin ang mga malalaking lupain ng mga mayayaman para ipamimigay sa mga nangungupahang magsasaka. Bagaman ayon sa (National Centennial Commission, 1999) “...But although Magsaysay emphasized the need for a "land reform bill,"... allowed a modest appropriation and authorization of a bond issue which limited expropriation to estates in excess of 300 hectares and corporate holdings of more than $600 . . . "$ Kahit pa man nito, taus-puso siyang nanungkulan pero sadyang mahirap ang kanyang gawain kaya hindi lubusang nagawa dahil hindi natingnan nang maigi ang mga iilang bagay. Nagpautang din ang pamahalaan sa mga magsasaka at natulungang bumangon muli sa kahirapan dahil na rin sa kanilang sariling sikap. Napasuko ng pamahalaan si Luis Taruc at natapos ang Huk na rebelyon.

Si Presidente Garcia naman nariyan ang "austerity measure", "Filipino First Policy" at muling pagbuhay ng sining at kultura. Ang "Austerity Program" ni Garcia ay panawagan sa striktong paggastos ng gobyerno lalo sa mga na-import na mga produkto mula Amerika. Ang Polisiyang "Pilipino Muna" ay pagpatibay sa kalayaan ng ekonomiya sa bansa at pagbigay ng proteksiyon sa mga negosyanteng Pilipino laban sa mga dayuhang mamumuhunan. Binago niya ang negosyo sa pagtitingi. Binuhay muli ni Garica ang kultura at binigyan ng parangal ang mga artist na matagal nang hindi napansin. Nabuhay ang Bohlen-Serrano Agreement na nagpaikli sa pananatili ng mga base-militar ng Amerika ng 25 taon mula sa 99 at maaaring i-renew kada 5 taon.

Sa administrasyong Macapagal nariyan ang Land Reform Code dahil sa kawalan ng lupa ng mga magsasaka. Dahil kulang ang paglaan at nariyan pa ang oposisyon ng mga may-ari ng malalaking lupain, kaunti lang ang pagbabago. Natapos din ang 'share tenancy system.' Nailipat rin ang araw ng Kalayaan ng bansa mula ika-4 ng Hulyo sa ika-12 ng Hunyo.

Nahubog ang pagkabansa ng Pilipinas sa mga senyas na ito sapagkat naipakita na sa mga panahong ito, ang 
bansa ay pilit ibinangon muli ng mga namumuno kahit mahirap-nariyan ang kakulangan sa pondo, ang pagpahirap ng mga Amerikano sa mga Pilipino at gusto nilang kontrolin ang ekonomiya, ang problema sa mga lupain at iba pa. Ang maganda ay pilit ipinaglaban ang karapatan ng mga Pilipino sa kanilang mga likas-yaman na dapat sila mismo ang dapat makinabang.

\subsection{Quezon and Osmeña administration}

Si Romeo Carlos at Norman Dreo ang mga pintor sa painting na ito. Si Romeo Carlos.

Ang Senyas ay ang kontribusyon ng dalawang presidente.

Sina Presidente Quezon at Presidente Osmeña ay mga Presidente ng Pamahalaang Komonwelt—sampung taong transisyon bago ibibigay ng mga Amerikano ang tunay na Kalayaan—kung handa na ang mga Pilipino na maging malaya. Buti na lang at nanalo ang mga Demokrats sa Amerika. Iyong ideyang Kalayaan ay nanghikayat sa mga nakababatang politikong mag-ambisyong sumabak sa pulitika, mga elitista, mga middle class gaya ni Quezon. Bilang Presidente ng Komonwelt, tiningnan niya ang magiging pundasyon para sa isang ganap na malayang estado. Kaya ang mga batas na ipinasa ay ang pagtatag ng Philippine Army, National Economic Council at ng Court of Appeals. Mahalaga ito para sa kapakanan ng bansa pati na iyong pagkaroon ng Pambansang Wika. Inagurahan din ang Social Justice Program para sa kapakanan ng pangkaraniwang tao. Nailipat rin ang UP sa Diliman mula sa Manila Campus at naitatag ang Tala Leprosarium (Carlos, 2014). Samantalang si Osmeña naman ang pumalit kay Quezon noong naging malaya na ang Pilipinas sa mga Hapon. Nagsilbi siyang pangulo hanggang sa magkaroon ng halalan at nang kumandidato, natalo siya kay Manuel Roxas. Tanyag siya sa pagiging isang statesman at maginoong tao na hindi pangkaraniwan sa kasaysayan. Sa ilalim ng pamamahala ni Osmeña, naging miyembro ang Pilipinas sa IMF at International Bank for Reconstruction and Development. Itinulak din niya ang Bell Trade Act at nang naging batas nabigyan ng pagkakataon ang bansa na makapagluwas ng mga produkto sa Amerika nang walang buwis.

Ang dalawang pangulong ito ay may malaking kontribusyon sa kauna-unahang pagpapalakad ng gobyerno. Ang tunguhing ito ay patikim pa lamang sa darating na kalayaan na naging batayan para sa pagbigay ng kalayaang pulitikal. Dito mas lalong nahubog ang pagkabansa ng Pilipinas sapagkat sa mga susunod na mga pangyayari matutunghayan sa wakas ang pagiging malaya ng bansa sa totoong kahulugan ng pagiging malaya.

\subsection{Quirino presidency}

Ang mga pintor sa likod ng painting ay si Romeo Carlos at Michael Velasco.

Ang Senyas ay ang kontribusyon ng presidente.

Nang namatay si Manuel Roxas bago matapos ang kanyang termino, si Quirino bilang Bise Presidente ang nanungkulan sa hindi natapos na termino ni Roxas. Bilang pangulo, pinilit niya ang Amerikano na gawing iron clad ang kanilang pagtanggol sa Pilipinas kung sakaling malagay sa panganib ang bansa, sa pamamagitan ng paghingi ng Mutual Defense Treaty na hanggang ngayon ay batayan ng pakipagkaibigan ng Pilipinas sa Estados. Naitatag din ang South East Asia Treaty Organization (SEATO) sa panahong iyon sa pag-igting ng Cold War. Ayon kay Dean Gloria Santos ng Philippine Historical Association, "Quirino is regarded as the Father of Foreign Service..." (Chua, 2015). Inaalala siya sa pamamagitan ng pagpangalan sa murang pabahay (Quirino District), ospital (Quirino Memorial Hospital), at grandstand (Quirino Grandstand). Ayon naman kay Carlos (2014), "I didn't know that President Quirino was very strong in the humanitarian aspect. He opened our country's door to the so-called "White Russians" who were being persecuted by Mao Tse Tung in China during the Cultural Revolution..."

Ang pagkabansa ng Pilpinas ay nahubog at mas nakilala bilang isang bansa sa Asya at naging matatag dahil sa pagtutulungan ng pamayanan ng mga bansa sa Asya at sa Estados Unidos. 
Senyas: Diskurso ng pagkabansa mula sa pangunahing materyal icon sa 29 na mga obra siningsaysay

5.14 The onset of the revolution

Ang pintor nito ay si Vincent de Pio.

Ang Senyas ay watawat na sagisag ng bansa.

Ang kulay ng bandila na nangingibabaw ang kulay pula sa painting ay nagpapahiwatig ng sobrang galit at rebelyon-iyong pagkakaisa ng mga Pilipino upang lumaban para sa kalayaan. Ayon kay De Pio (2013), ang KKK na nakapalibot sa ulo ni Rizal ay sumasagisag ng korona, ang Utak ng Rebolusyon. Totoo sapagkat bagaman hindi talaga gumamit ng dahas si Rizal pero siya ang lider ng Propaganda at isa sa mga nukleus ng kilusan na tila sumisindi sa mga nagbabagang damdamin. Dagdag pa ni De Pio (2013), “...The composition in red symbolizes the ups and downs of the revolution." Maaaring sobrang kasiyahan, pagdadamayan, kaisahan, galit, pighati, kalungkutan at karahasan ang puwedeng iugnay sa kulay na pula.

Ang watawat ang pinakamamahal na simbolo ng Pilipinas. Ito ang sagisag ng kalayaan, ng pagkamakabayan, pambansang pagkakaisa, pagmamahal sa bayan at pambansang kasarilan. Ito ang mga humuhubog sa pagkabansa ng Pilipinas — ang mga simbolong ito. Nagpapakita ito ng soberanya ng Pilipinas.

\subsection{Building from the ashes}

Si Norlito Meimban ang pintor sa painting na ito.

Ang Senyas ay mga kontribusyon ng mga presidente.

Sa administrasyon ni Roxas itinaas ang Watawat ng Pilipinas at ibinaba ang Watawat ng Amerika. Dito nasaksihan ni Presidente Roxas ang pagwakas ng pananakop ng mga Amerikano at kusang pagbigay ng matagal na inaasam-asam na Kalayaan sa Pilipinas noong Hulyo 4, 1946. Dahil ito sa Jones Law na kilalanin din ang kasarinlan ng Pilipinas sa loob ng ilang taon at Tydings-McDuffie Law na magkaroon muna ng 10 transisyon para mapaghandaan ang pinakmimithing kasarinlan.

Ang Pangatlong Republika ay ang totoong Kalayaang pulitikal kung saan kinilala na sa buong mundo ang soberanya ng Pilipinas. May kapangyarihan na rin ang estado na pamahalaan at puwede nang pasunurin ang mga tao sa loob ng teritoryo nito. Ang inagurasyon nito ang simula sa katuparan sa mahabang pakikibaka para sa kasarinlan. Sa wakas natamasa na rin ng mga Pilipino ang pagiging malaya.

Isinagawa ni Roxas ang mahirap na responsibilidad sa pag-ayos at pagbuo muli ng bansa na nasira dahil sa digmaan. Walang pera din ang bansa. Humingi ng tulong pinansyal ang bansa at kapalit nito ang Parity Rights na magbigay ng pantay na karapatan sa mga Pilipino at Amerikano na gamitin at pakinabangan/pagsamantalahan ang mga likas na yaman. Dahil sa patakarang ito madaling napaunlad ang industriyang pangangalakal na itinayo ng mga Amerikano. Doon nagumpisa ang ugnayan ng Amerikano at Pilipino, kooperasyong pang-ekonomiya at pagbigay ng mga karagdagang paraan upang magtulungan sa anumang kaharaping isyung bilateral, rehiyonal at global.

Humuhubog ang mga ito sa pagkabansa ng Pilipinas sapagkat naitaguyod ng lider ang bansa upang maihaon sa kahirapan ang mga mamamayan, at ang katangiang palaban na ano mang dagok ang darating sa buhay ay hindi susuko!

5.16 The Filipino struggle for Philippine independence

Ang artist sa painting na ito ay si Aileen Lanuza.

Ang Senyas ay watawat na sagisag ng Pilipinas.

Kinuha ng kasalukuyang pambansang watawat ang iba't ibang anyo at katangian ng lahat ng mga naunang 
Watawat ng Katipunan. Ang gintong-dilaw na araw sa gitna ng puting tatsulok ng pambansang watawat ang talagang nanatili sa kabila nang paiba-iba ng watawat ng Pilipinas (Arevalo, 2012). Nagkaroon ng siyam na watawat bago ang kasalukuyang watawat. Ang kasalukuyang watawat ay ang unang iwinagayway sa balkonahe ng tahanan ni Emilio Aguinaldo noong Hunyo 12, 1898 sa Kawit, Cavite (Arevalo, 2012).

May iba't ibang kulay ang disenyo ng watawat na may kahulugan at simbolo—ang Puti ay kalinisan, ang Tatsulok naman ay pagkapantay-pantay at pagkakapatiran, ang Asul ay nagsisimbolo ng kapayapaan, katotohanan at katarungan, ang Pula ay pagiging makabayan, kabayanihan at kagitingan ng bawat Pilipino na ipaglaban ang sariling bayan, samantalang ang Araw naman ay ang malaking hakbang na ginawa ng mga Pilipino upang makamit ang daan patungo sa kaunlaran at kabihasnan, ang walong Sinag ay ang Manila, Bulacan, Pampanga, Tarlac, Batangas, Laguna, Cavite at Nueva Ecija — ang mga probinsya na unang nag-aklas laban sa Espanya at ang tatlong Bituin naman ay ang Luzon, Visayas at ang Mindanao (Malacañang Palace, Presidential Museum and Library, n.d.).

Disenyo ni Aguinaldo ang watawat nang ipinatapon sa Hongkong at itinahi naman ito ni Donya Marcela Agoncillo, sa tulong ng kanyang anak na si Lorenza at ni Delfina Herbosa de Natividad. Gawa sa silk ang watawat (Arevalo, 2012).

May mga kontrobersiya ang bandila. Noong sinakop na ng mga Amerikano ang Pilipinas, nagkaroon ng hidwaan ang mga Amerikano at mga Pilipino kaya ipinatupad ng Philippine Commission ang Flag Law of 1907 na ipinagbawal na gamitin ng mga Pilipino ang bandila at ipakita kahit saan (Malacañang Palace, Presidential Museum and Library, n.d.). Pero napawalang bisa din ang batas. Naging kontroberisya din ang lilim na bughaw na ginamit. Mula 1920 hanggang 1985, ang lilim ay navy blue hanggang sa inutos ni Pangulong Marcos na baguhin ito sa lilim na sky blue. Maraming pa ang nangyari hanggang sa naipasa ang Republic Act No. 8491 at ang kulay na ay marahan naman sa navy blue na ginamit hanggang ngayon (Malacañan Palace, Presidential Museum and Library, n.d.).

Ano man ang mga kontrobersiya noon ay hindi iyon hadlang kung paano titingnan ang watawat sapagkat ito ay nagsilbing simbolo ng pagkakaisa. Ang pinakamahusay na paraan upang malaman ang isang bansa ay sa pagtingin ng kahulugan ng bandila nito. Malaking bagay ito sa pambansang pagkakakilanlan. Kung wala nito, wala ring bansa. Ang bandila ay sagisag ng kalayaang ipinaglaban ng mga matatapang na Pilipino na handang magbuwis ng buhay para sa Inang Bayan.

\subsection{Occupied Philippines}

\section{Si Julius Samson ang artist ng painting na ito.}

Ang Senyas ay ang diskursong labanang pandagat sa Golpo ng Leyte.

Apat na magkaibang labanan ang pangyayaring ito na nangyari sa Leyte, Samar at Luzon. Nangyari ang labanang ito pagkatapos dumaong si Heneral Douglas MacArthur sa Palo Beach ng Leyte kasama si Sergio Osmeña, Carlos P. Romulo at mga Allied Force noong Oktubre 20, 1944. Natupad ang "I shall return." Sinabi ito ni MacArthur sa estasyon ng tren sa Australia, hindi sa Pilipinas (Balestrieri, 2019). Nanalo din sila sa labanan dahil sa malaking suporta at kagitingan ng mga US Navy 3rd at 7th fleet na ginawa ang lahat para maging matagumpay ang Leyte Landing.

Umabot sa 100,000 square miles ng karagatan ang labanan. Ang lumaban dito ay ang mga pinakamalaking barkong pandirigma sa buong kasaysayan ng mga Hapon — ang Yamato at Musashi, siguro ang pinakabigat at pinakaarmadong barkong pandirigma. Pero nalunod at nasira ang dalawang ito sa mga eroplano ng mga Amerikano. Mga 800 na barko at 1,800 na eroplano ang kasali sa labanan. Lumubog ang 337,000 tonnage na mga barko. Malaking pagkatalo talaga ang Labanan sa Golpo para sa Hapon. Mas maraming sundalong Hapon ang namatay. Sa labanang ito, naglunsad ng kauna-unahang organisadong Kamikaze ang mga Hapon. Gusto pa 
Senyas: Diskurso ng pagkabansa mula sa pangunahing materyal icon sa 29 na mga obra siningsaysay

rin sana nila na ipagpatuloy ang labanan bagaman sa pagbomba ng Nagasaki at Hiroshima kung hindi lamang naparalisa ang kanilang lakas pandagat. Nangyari ito dahil sa pangako ni MacArthur maliban doon sa moral na obligasyon ng mga Amerikano na palayain ang Pilipinas (Abrugar, 2014). Hindi lang sila nakabalik agad sa Pilipinas dahil inuna nila ang pagpalaya sa California. Nagpaalala ang Leyte Landing sa mga pangyayari noong Oktubre taong 1944 — napalaya ang Pilipinas at natapos ang digmaan. Hindi lamang Leyte ang pinalaya kundi buong Pilipinas kaya dapat sana ang pagdiriwang ng Leyte Landing ay hindi lamang sa Leyte kundi sa buong Pilipinas din.

Nahubog ang pagkabansa ng Pilipinas dahil nagkaisa ang mga Pilipino laban sa Hapon bagaman hindi lahat ay nakasali pero nakiisa sa isip at salita. Watak-watak man ang mga isla pero buo ang isip na sila ay iisang bansa lamang. Sa pagsusuri ng kasaysayan lalo na iyong tungkol sa mga digmaan, nagkakaroon ng kamalayan ang mga Pilipino kung paano sila kumilos sa mga panahong ito na nagpipinta kung anong klaseng tao sila, paano nila ginugunita ang mga pangyayari at ano man ang kanilang mga salaysay sa mga alaala ay pagpapahayag ng kanilang pambansang katangian.

\subsection{The battle of Mactan and Christianization}

Ang pintor sa painting na ito ay si Amado A. Hidalgo.

Ang Senyas ay ang katapangan ni Lapu-lapu at mga Pilipino.

Naipakita sa tema ng painting ang katapangan na gustong ipakita ng pintor-ang katapangan ng kauna-unahang lider na lumaban sa mga dahuyan. Pinakita ang katalinuhan ni Lapu-Lapu siyempre kasama ang kanyang mga kawani gamit ang bolo, sibat, palaso at pana laban sa mas sopistikadong sandata ng mga Espanyol. Pero ano nga ba talaga ang mga pangyayari sa likod ng pinakatanyag na Labanan sa Mactan? Ang pananakop ng Pilipinas sa mga Kastila ay kalimitang napabayaang paksa sa kasaysayan ng Pilipinas bagaman marami itong interpretasyon lalo na sa aspetong militar na karamihan naman ay may bias.

Ayon kay Angeles (2007), “...the Europeans did not fight in Mactan according to their own discourse on war. Yet, the battle of Mactan is the most famous engagement in the Spanish conquest, is perceived to be illustrative of pre-Hispanic Philippine martial ability...” Totoong marami diskurso ang dapat isaalang-alang sa labanang ito, pero isang bagay lamang ang nanaig sa Labanan sa Mactan — ang pagkapanalo ni Lapu-Lapu at mga katutubong Pilipino laban kay Magellan at kanyang mga kasama. Naisahan ni Lapu-Lapu si Magellan habang minaliit niya ang kakayahan ng mga katutubo. Nagpatalo kay Magellan ang mga estratehiyang ginamit ni Lapu-Lapu at ang kahandaan ng mga kasamahan niya sa pinakaunang laban sa mga dayuhan.

Nahubog ang pagkabansa ng Pilipinas sapagkat nagpapakita ito ng matinding katapangan at katalinuhan na likas sa mga Pilipino na palaban upang ipagtanggol ang lupang tinubuan.

\subsection{Pambansang bangka}

\section{Si Simkin S. De Pio ang pintor sa painting na ito.}

Ang Senyas ay ang paglalayag ng bangka na tinawag na balangay.

Ang Pamayanan noon ay maaaring ilarawan sa pagtatalakay sa mga kabuuang sosyo-pulitikal ng mga Pilipino sa panahong yaon. Ang balangay ay madalas napagkamalang isang uri ng pulitikal na yunit sa kasalukuyang panahon, ngunit ito ay isang pagbuklod ng isang angkan na ang pangunahing layunin ay ang pagpataas ng produksyong agrikultural. Tumutukoy sa bangka ang salitang balangay. Komunidad ito ng mga kamag-anak na pinamumunuan ng isang datu. Sa simula puwede silang maisakay sa isang balangay na kayang magpasakay ng maraming pamilya na magkakamag-anak. Dito rin hinango ang salitang "barangay" na naglalarawan sa pamayanan ngayon. Ang balangay na tinatawag ding bangkang Butuan ay isa sa mga pinakamatandang sasakyang-pandagat sa bansa na salamin at tatak ng lahing Pilipino (Deleno, 2020). Ang 
Capulla, R. P., \& Demeterio, F. P. A., III

balangay ay nagpapakita ng angking galing ng mga Pilipino sa paggawa ng nga mga bangka, pati na rin sa paglayag sa karagatan noong pre-kolonyal.

Kuwento ng paglipat (migration) ng mga sinaunang tao ang bangka. Ito lang ang nag-iisang mahalagang kasangkapang ginamit sa pagtulay ng mga pamayanan upang makipagpalitan o transportasyon. Ang mga Pilipino ay napabilang sa Austronesian Race na magagaling na tagagawa ng bangka. Ang pagkakaroon ng mga tao sa Pilipinas ay nakaangkla sa teoryang pagkakaroon ng bangka. Mapapansing mayroong mga pamilyang ginawang tahanan ang bangka na tinangkang wasakin ng isa at maraming bagyo pero matatag ang integridad ng mga pamilyang ito. Maaaring maging kuwento din ito ng mga Pilipino ngayon. Ito ang humuhubog ng pagkabansa ng Pilipinas at ng mga Pilipino - ang identidad na ito.

\subsection{Galleon trade}

Ang pintor sa painting na ito ay si Jonahmar A. Salvosa.

Ang Senyas ay ang naratibo ng Kalakalang Galyon at ang Pilipinong gumawa ng barko.

Ang Kalakalang Galyon ay kalakalan ng Mehiko at Pilipinas. Ang mga gumawa ng mga naglalakihang barko ay ang mga Pilipino noon na mga bihasang manggagawa. Tumagal ang Kalakalan ng dalawa at kalahating daang taon kaya ang tagal pala nilang gumawa nito. Napakahusay at napakatiyaga ng mga sinaunang Pilipino na hindi ininda ang hirap at pagod. May pagpapalitan din sa kalakalang ito gaya ng mga produkto galing Tsina gaya ng mga gawa sa silk, porselana at marami pang ibang produkto na ibinenta sa Mexico kasama ang produkto sa Pilipinas at mga produkto naman sa Mexico gaya ng silver coins at marami pang iba ay ibinenta naman sa Pilipinas. Ito ang pinagkakitaan ng mga Kastila.

Nahubog ang pagkabansa ng Pilipino sapagkat hindi maipagkaila na kahit noon pa man ang gagaling na talaga ng mga Pilipino, kahit saan puwedeng isabak. Kahit sa giyera. Hindi biro ang paggawa ng mga naglalakihang barko noon — ang pagod, hirap, wala pang sahod at mapalayo pa sa pamilya ay hindi talaga matatawaran. Sino naman ang nakinabang? Walang iba kundi ang mga dayuhan lamang.

\subsection{Pre-historic material culture}

\section{Si Benjie Cabangis ang pintor sa painting na ito.}

Ang Senyas ay ang Banga ng Manunggul.

Ang mga Austronesyano na pinanggalingan ng mga Pilipino ay gumagawa ng mga bangka. Kaya alam ng mga sinaunang Pilipino ang konseptong paglalakbay gaya ng ipanapakita sa Banga ng Manunggul. Ginagamit nila ang banga sa pangalawang paglilibing. Sa banga may dalawang pigura sa tuktok ng takip, ang isa na nasa likod ang nagsasagwan ng bangka at ang nasa harap ay tila bangkay na nakatiklop na paekis ang mga kamay sa dibdib. Pinaniwalaang inihatid nito ang kaluluwa ng yumao sa kabilang buhay. Napakahusay nito at isa itong halimbawa ng pananampalataya ng mga Pilipino noon tungkol sa kabilang-buhay kaya hindi nahirapan ang mga Espanyol sa pagpaniwala ng mga tao tungkol sa ideyang buhay ng walang hanggan.

Ang sekundaryang paglilibing ay ginagawa sa pamamagitan ng paglilipat ng labi ng namatay mula sa orihinal na kinalalagyan nito patungo sa bago (Tapayang, Manunggul, 2015). Itinuturing ang Banga ng Manunggul na isang Pambansang Kayamanang Pangkultura.

Ang mga kulturang ito ay humuhubog sa pagkabansa ng Pilipinas sapagkat ito ang identidad ng tunay na Pilipino noon. Mayroon na silang mayamang kultura noon na hindi puwedeng ibalewala lamang-na manlalakbay lamang ang lahat sa mundong ito. Sa ayaw man ng iba, lahat ay mamamatay! 
Senyas: Diskurso ng pagkabansa mula sa pangunahing materyal icon sa 29 na mga obra siningsaysay

5.22 Angono petroglyphs

Si Junyee ang pintor sa likod ng painting na ito.

Ang Senyas ay ang masining na ugat ng mga Pilipino.

Ang kasaysayan ay pag-aaral ng mga talaan ng mga nakaraang pangyayari, at nag-umpisa ito noong naimbento na ng tao ang sistema sa pagsulat. Dahil sa sistemang ito, ang nakaraan ay naitala at naipasa sa kasalukuyang henerasyon. Sa Pilipinas, ang pinakaunang patunay ng sistema sa pagsulat ay matatagpuan sa petroglyphs ng Angono, Rizal. Makikita ito sa yungib na gawa ng volcanic tuff na may isang daan at dalawampu't pitong larawang inukit sa pader ng yungib. Noong 1973, idineklara itong National Cultural Treasure at noong 1985 inilista sa World Inventory of Rock Art. May materyal na kultura na noon bago natuklasang muli ng mga dayuhan. Kaya hindi nila puwedeng matawag-tawag na sila (Kastila) ang unang nakadiskubre ng Pilipinas.

Makikita na mayroon nang dugong masining na dumadaloy sa mga ugat ng mga Pilipino noon bago pa naitala ang kasaysayan. Kung mayroon nang mga artist noon pa man, mas lalo na ngayon na marami na ang maaaring mapagkukunan (resources), mga organisasyon at mga taong gustong mapanatili ang pamana ng kultura. Ito ang tatak Pilipino na likas na magagaling at may angking talento na puwedeng ipagmayabang sa buong mundo. Nahubog ang pagkabansa ng Pilipinas sapagkat may mayamang kultura ang bansa na puwede palang pag-aralan nang sa gayon ay lalo pang maintindihan ang bansang kinagisnan.

\subsection{The ghosts of the future}

Ang pintor sa painting na ito ay si Gig C. De Pio.

Ang Senyas ang pagkamahilig ng mga Bisaya sa mga tato.

Ang Pilipinas ay mayaman sa iba't ibang uri ng mga pangkat etno-lingwistiko na may kanya-kanyang wika, kultura, paniniwala o relihiyon. Bawat pamayanang katutubo ay magkaiba depende kung saan sila naninirahan at anong klaseng klima meron sila. May mga tribong maliliit at merong malalaki-Luzon, Visayas at Mindanao.

Kilala sa pagkahilig sa pagtato ng kanilang mga katawan ang mga Bisaya, lalaki man o babae (mas maraming tato-mas maganda). Pangunahing bahagi ito ng kanilang katutubong kultura. Halos lahat ng parte ng katawan nila ay may tato. Para sa mga Pintados, upang maipakita ang kanilang katayuan sa buhay, gumuhit sila ng disenyo gamit ang matalas na bakal na pinainitan sa apoy. Tanda ito kung gaano sila katapang at ano ang katayuan nila. Ang pinakamatapang na mandirigma ay may pinakamaraming disyenyo mula ulo hanggang paa at sa kalikasan ang inspirasyon nila. Kaya lang sa panahon ng 1700s ay halos nawala ito dahil sa pananakop ng mga Kastila. Ayaw nila ng tato. Ayon kay Cornwell (2020), "Now, true Filipino tribal tattoos are a rarity...," tiyak dahil doon. Subalit mayroon paring matatagpuan na gumagamit ng sinaunang pagtatato ngayon pero bihira na lamang sapagkat matatanda na rin ang nagtatato dati, ang mga orihinal. Pero marami na rin ang nagpatato sa Amerika at Canada ngayon kasi miyembro sila ng Babaylan Studies Center at talagang alam nila na ang mga katutubong Pilipino ay mahilig sa tato bago ang kolonisasyon. Nakita ito mismo ng mananaliksik nang pumunta siya sa ibayong dagat. Ayon sa kanila ginawa nila ang pagtato upang ipakita ang kanilang identidad.

Makikita sa gitna ng painting na para bang mga multo (puting guhit). Ang imaheng puti ay may mga kamay na humuhugis ng mga pigura ng mga matipunong Pintados na kumalaban sa mga Kastilang sundalo. Sabi ni De Pio (2015), “...What we didn't know also is that most of the Visayans were pintados including the people from northern Mindanao..."

Mabuti na lang at binuhay muli ang alaala ng pagiging Pintados ng mga taga-Bisaya dahil sa Pintados Foundation, Inc. noong 1986. May Pintados Festival taun-taon sa lungsod ng Tacloban bilang paggunita sa mayaman at makulay na kasaysayan ng mga taga-Bisaya. Humuhubog ito ng pagkabansa ng Pilipinas sapagkat 
Capulla, R. P., \& Demeterio, F. P. A., III

napapahalagahan ang identidad ng Pilipino na sadyang kinahihiligan ang sining noon at magpahanggang ngayon.

5.24 The west discovers the Philippines

Si Armando D. Bacaltos ang pintor sa painting na ito.

Ang Senyas ay ang kolonyalismo sa bansa na nagpadagdag sa kamalayan ng mga Pilipino kung sino at ano sila.

Ang konsepto ng kolonisasyon ay naipakita sa mga materyal na icon, ng isang malinaw na pagtukoy sa kolonyal na stratehiya: "Ang dikotomiya ng Espada at Krus sa proseso ng kolonisasyon”-magkasalungat na bagay pero ginamit ng mga Espanyol para sa kanilang imperyalismong layunin. Ipinamalas ang pagpalaganap ng Kristiyanismo sa pamamagitan ng pagtayo ng Krus sa Cebu ni Magellan, pagbinyag ng mga Pilipino, pagtatag ng mga simbahan sa kapuluan at iba pa. Ginamit naman ang 'lakas' ng mga Espanyol kung sakaling makipaglaban ang mga Pilipino. Ang mga misyonerong Espanyol at ang relihiyong Katolisismo ay naging makapangyarihang 'sandata' ng mga Espanyol sa kanilang pananakop. Hangad rin nilang makamit ang karangalan at kapangyarihan bilang nangunang bansa sa paggagalugad ng mga bagong lupain para sa lalo pang ikatatag ng Monarkiya ng Espanya-iyan ang 'korona.' Ito ang pinakamabigat na kuwento kung bakit naiba ang tadhana ng Pilipinas na napakalayo sa mga inaasam-asam na buhay ng mga naunang Pilipino. Pero ang kuwentong ito ang nagbigay ng mabuting pang-unawa sa pagkakakilanlan sa kontemporaryong Pilipinas kaugnay nitong kolonyal na nakaraan.

Hindi na maaaring balikan ang nakaraan at kailangan na lamang itong lubusang pag-aralan. Isa sa mga pag-aaral ngayon kung paano makamit ang dekolonisasyon ng mga Pilipino sa bansang Amerika at muling pagsakatutubong proseso ng mga Pilipino ay ang Center for Babaylan Studies (Bridges those in the diaspora with living babaylan in the Philippines and in indigenous living traditions) na isang Non-Gonvernmental Organization (NGO). Nakapagdalo ang mananaliksik sa kanilang internasyunal na kumperensiya na ginanap sa Canada noong taong 2019. Kamangha-mangha rin ang kanilang mga adhikain pero siyempre magkaiba parin ang mga pananampalataya nila sa manananaliksik. Sa kabuuan, maganda ang hangarin nila upang malaman kung saan lulugar ang Pilipino sa mundo. Ito ay humuhubog sa pagkabansa ng Pilipinas.

\subsection{The Sarimanok as cultural symbol}

Ang pintor sa painting na ito ay si Abdulmari Asia Imao.

\section{Ang Senyas ay ang Sarimanok.}

Ang Sarimanok ay Simbolo ng Kultura ng Mindanao at ng buong Pilipinas. Isa itong Mitikong ibon ng Maranaw at sumisimbolo ito ng kanilang sining. May makukulay na pakpak at balahibo ang Sarimanok na may mahabang buntot at ang kagat o saklot na imahen na isang isda ang nasa tuka nito. Ang Sarimanok ay madalas na pangunahing mga disenyo ng okir. Napakagandang tingnan ang okir. May nagsabi ring simbolo ng suwerte ang Sarimanok. Ito ay nagmula sa isang alamat ng sinaunang panahon at impluwensya ng Islam na nanguna na sa Pilipinas ng higit isang daang taon at malaki ang kontribusyon sa Kulturang Pilipino. Ayon sa pintor na si Imao (2104), "Nakilala ako sa motif na Sarimanok. Ginamit ko ito as cultural symbol ng Mindanao at ng buong Pilipinas."

Dapat ding isipin pala na ang Muslim Art ay iba sa Islam Art. Ang Islamic Art ay nagpahayag ng tawhid o ideya ng Islam sa pagsamba sa isang Diyos. Ang Muslim Art naman, ang halimbawa nito ang "Muslim Betrothal" ni Carlos "Botong" Francisco na naglalarawan ng kasal sa Muslim o gaya ng sariling larawan ni Sakili, isang propesor ng arts and humanities sa UP CAL at nagdesinsyo ng UP's Sablay, ay hindi nagpahayag ng tawhid. Ladrido (2018), ayon kay Abraham Sakili: "There are 13 muslim groups in the Philippines so each group excels in different art forms..."

Ang kulturang ito ay nagbigay ng pagkakakilanlan sapagkat bahagi din ang Muslim sa lahing Pilipino.

108 Consortia Academia Publishing (A partner of Network of Professional Researchers and Educators) 
Senyas: Diskurso ng pagkabansa mula sa pangunahing materyal icon sa 29 na mga obra siningsaysay

Nahuhubog ang pagkabansa sapagkat bagaman makikita ang mga pagkakaiba-iba ng kasarian at etnisidad ng Pilipinas, nagkaroon paring pagkahubog ng bansa (nation-building).

\subsection{Tatak Pinoy}

Si Denes V. Dasco ang pintor sa painting na ito.

Ang Senyas ay tatak Pinoy! ang bahay-kubo.

Ang icon ay nagsisilbing tanda o badge ng pagkakilanlan ng bansa. Maraming mga icon ang bansang Pilipinas gaya ng mangga, barong, sampaguita, ang Agila, bangus, bakya, Tamaraw, Anahaw, baro't saya, bahay kubo at marami pang iba na hindi naman opisyal na naideklara na mga icon. Isang magandang karanasan kung babalikan at titingnan muli ang mga sagisag na kumakatawan sa pagkakakilanlan ng bansa.

Ang bahay kubo - ang "Pambansang Tirahan ng Pilipinas." Isang pamana ng kultura ang bahay kubo at sagisag ito ng pagkakaisa ng mga Pilipino at ng pamilya. Sinasabing ang bahay kubo ay kumakatawan sa katatagan ng mga Pilipino dahil agad silang makaahon muli kahit dumaan ang bagyo, lindol at iba pang kalamidad pati pandemya at ang pagiging malapit ng mga Pilipino sa kalikasan (NCCA Official, 2015). Nakikita din ang pagkasimple ng mga tunay na Pilipino at bukas ang loob sa ano mang puwedeng dumating sa buhay ng tumatahan dito at higit sa lahat ang pagkakaisa ng pamilya sa hirap at ginhawa. Iyan ang tanda ng pagka-Pilipino! Tatak Pinoy. Ang mga ito ay humuhubog sa pagkabansa ng Pilipinas.

5.27 The journey continues

Ang pintor sa likod ng painting na ito ay si Grandier Bella.

Ang Senyas ay mga kontribusyon ni Presidente Arroyo.

Marami ang nagawa ng Gobyerno sa panahon ni Macapagal-Arroyo. Naitayo at naiayos ang mga kalsada, tulay, sakahan-patungong-sakahan na mga daan, pantalan, paliparan at iba pang mga imprastraktura. Nagkaroon ng mga reporma sa produkto/pinansiyal na merkado. May mga RORO na barko. Maraming manggagawa sa panahong iyon. Dumami ang mga nars na gustong pumunta ng USA dahil noong 2000 itinaguyod ni Arroyo na maging komportable ang buhay nila kung makapunta sila sa "land of milk and honey." Kaya lang noong nagkaroon ng pag-urong (recession) sa Amerika, nahinto ang paglipat ng mga nars doon. Pero bago iyon, marami nang eskuwelahan ang nag-alok ng BS Nursing noon at nakapagtrabaho din naman ang mga nars bilang mga Clinical Instructor. Nagkaroon ng problema dati sa dami ng mga nars at kawawa ang ilan sa kanila sapagkat ginawa ang lahat ng mga magulang para lang makapag-aral at hindi pa sila agad makapunta sa Amerika. Sa BPO naman, nanguna ang Pilipinas sa destinasyon nito at naging kabisera ng call center sa buong mundo. Noong nagkaroon ng global na recession sa ibang bansa, maraming mga OFW ang nawalan ng trabaho kaya nagkaroon ng mga training para sa kanila upang maging ahente ng call center.

Hindi maipagkaila na dumami ang mga OFW noon. Nang nasakop na ng Office of the President ang Commission of Filipinos Overseas (CFO) noong 2010, mas naging aktibo ang CFO sa mga isyung paglipat at pag-unlad kaya nagresulta ang nabagong polisiyang ito ng mas maraming Filipino diaspora at maraming mga stakeholder (OECD, 2017). Dumami din ang mga iskolar ng DOST-MS and PhD para magkaroon ng maramihang produksyon ng mataas na nibel na manpower sa siyensa at teknolohiya. Naipasa din ang Technology Transfer Act ng 2009 na nagpadali sa paglipat ng teknolohiya sa bansa at komersiyalisasyon ng mga pananaliksik na pinondohan ng gobyerno. Nagkaroon ng pagpapatibay sa R\&D. Dinala ni Macapagal-Arroyo sa 'Golden Age' ang DoST.

Sa kabila ng mga pangyayaring ito, natugunan kaya ang mga hinaing ng mga mahihirap? Ang sagot ay malaking hindi! 
Nahuhubog ang pagkabansa sapagkat ipinapakita ang mga karanasan ng mga ordinaryong Pilipino—ang mga manggagawa. Nagkaroon ng pagkakakilanlan ang mga Pilipino na mga dakilang manggagawa at matatalino na handang magsakrispisyo para sa ikabubuti ng pamilya at sa bayan.

\subsection{Batas militar}

Ang pintor sa painting na ito ay si Pablo Ben Santos.

Ang Senyas ay Batas Militar at epekto nito.

Ang pagdeklara ni Presidente Marcos ng Batas Militar ang pinakamadilim na sandali(?) ng bansa sa kasaysayan. Dahil dito naghirap ang mga Pilipino. Marami ang mga pangyayari—katakot-takot, karumaldumal, kahindik-hindik, nakakadiri at iba pa. Nagumpisa ang lahat dahil sa "pagbomba ng Plaza Miranda." Pero bago iyon magulo na ang bansa. Nariyan ang aktibismo ng mga estudyante, political unrest, pananakot na magkaroon ng pagpalit ng Komunista sa bansa, kaguluhan sa Mindanao at alyansa ng partido ng oposisyon at Partido Komunista na may balak ibagsak ang bansa. Ito ang mga dahilan ng pagtatag ng Martial Law. Tiningnan ito bilang paraan para patahimikin ang mga oposisyon at pagsamahin ang kapangyarihan ni Marcos. Bagaman may mga sariling dahilan si Marcos, sapat ba iyon upang pahirapan ang kanyang mga kababayan? Tungkol naman sa Plaza Miranda Bombing, iba-iba ang naratibo tungkol dito.

Ang lahat ng mga pangyayari mula noon hanggang ngayon ay nagpapakita na ang sobrang kapangyarihan ay walang magandang kinahihinatnan. Kung magkakaisa lamang ang lahat at magbibigayan na mayroon man lang makain ang bawat Pilipino at magkakaroon ng respeto sa bawat isa, tiyak na mabubuhay nang mapayapa ang lahat.

Humuhubog ang mga ito sa pagkabansa ng Pilipinas sapagkat ang kaalaman sa kung ano ang mga pangyayari sa bansang kinagisnan —ang nakaraan ay napakaimportante upang magsilbing gabay sa isang matagumpay at magandang kinabukasan. Matingnan ang bansa sa isang mabuting perspektibo para kung ano mang mali ang napagdaanan, hangga't maaari ay maiiwasan.

\subsection{Celebration}

Ang pintor sa painting na ito ay si Romeo San Antonio Carlos.

Ang Senyas ay ang pagdiriwang ng kapistahan ni Señor Santo Niño ng Cebu.

Ang kapistahan ay pagdiriwang ng pasasalamat at pagbibigay karangalan sa mga patron ng mga santo sa isang bayan. Ginagawa ito taon-taon bilang pasasalamat sa mga biyayang natanggap at tagumpay na nakamit. Ang Kapistahan ni Señor Santo Niño ng Cebu na tinatawag na Sinulog ang titingnan lang dito. Naging pang-akit sa mga turista ang pagdiriwang na ito at sumasalamin sa mayamang kultura. May kasaysayan ang kapistahang ito at napapanatili ang pagdiriwang hanggang ngayon. Gaya ng pagbigay ng orihinal na imahen sa Batang Hesus kay Rajah Humabon. Hindi pala Señor Santo Niño sa Praga ang ibinigay kundi iyong Señor Santo Niño mula sa Espanya. Ang pagsamba sa batang Hesus ay pinaniwalaang nagsimula sa Espanya kaya nang napunta si Magellan sa Cebu noong 1521, dala-dala niya ang imahen ng bambino Hesus at ibinigay sa asawa ni Rajah Humabon. Hanggang ngayon ang batang Hesus ay sinasamba pa ng mga Pilipino at sinasayawan. Ito ang pinakatanyag na Sinulog sa Sugbu na dinadayuhan ng maraming tao sa buong mundo!

Ang mayamang kasaysayan at kultura ng Pilipinas ay sobrang dami at kulang ang isang pananaliksik na papel kung ilalagay lahat. Sabi nga ni Carlos (2014). "The main challenge really here is to depict history that entails a lot of details. In this case, I really have to do a lot of research...considering the work has a lot of disparate images I need to integrate into one cohesive whole."

Humuhubog sa pagkabansa ng Pilipinas ang kulturang ito na nagmula pa noon at nagpapatuloy pa hanggang 
Senyas: Diskurso ng pagkabansa mula sa pangunahing materyal icon sa 29 na mga obra siningsaysay ngayon.

\section{Ang mga naging karansan ng mananaliksik}

Sa deskriptiv na pananaliksik mahalaga ding malaman ang karanasan ng mananaliksik sa mga obra ng pintor. Unang-unang titingnan muna ang kanyang identidad. Isa siyang estudyante sa gradwadong paaralan na kumukuha ng Araling Filipino-Wika, Medya at Sining. Kailangan niyang isumite ang isang pananaliksik sa isang asignatura sa De La Salla University-Manila (DLSU). Iminungkahi ng kanyang kaibigang propesor na gawan ng pag-aaral ang mga painting sa Gateway Gallery.

Pinuntahan ng mananaliksik ang mga painting sa Gateway Gallery at tamang-tamang nadatnan pa ang mga artist na nagmiting noon. Huwebes ang iskedyul nila para sa kanilang on the spot-painting. Nakausap niya si Romeo Carlos, isang artist at kasalukuyang presidente ng UP Alumni Association. Pinuntahan siya ng mananaliksik sa UP Diliman Campus upang bilhin ang kahuli-hulihang librong nailimbag ng SiningSaysay. Marami ring naibahagi si Carlos sa mananaliksik na maaaring gamitin bilang mga datos. Matinding riserts at pagbasa ang ginawa ng mananaliksik upang mabuo sa wakas ang pag-aaral. Sinuri at pinag-aaralan ang mga pangunahing materyal na icon kasama na ang interpretasyon nito at tiningnan ang mga nakatagong diskurso sa likod ng mga painting. Naranasan ng mananaliksik na marami palang puwedeng maisip kung pagtutuunan ng pansin ang mga painting na minsan ay binabalewala lamang ng iba.

\section{Kongklusyon}

Ang paghahanap ng diskurso sa mga materyal na icon sa isang obra ng sining ay pagpapatibay lamang sa patuloy na pagpapahalaga sa kasaysayan ng Pilipinas. Ang kamalayang ito ay napakahalaga sapagkat humuhubog ito sa pagkabansang Pilipino.

Nagamit ng mga artist ang kanilang dakilang obra upang mahubog ang pagkabansa ng Pilipinas na nagpapatunay na ang sining ay pang-nasyunal at totoo talaga ang sinabi ni Matos na "All real art is national simply because international art cannot exist since there is no international artistic expression."

Nagawan ng matrix at naitala sa Pigura 4 ang lahat ng mga pangunahing materyal na icon sa mga piling obra ng SiningSaysay.

May mga kahulugan at/o interpretasyon ang mga materyal na icon gamit ang Senyas ni Barthes. Ang mga naratibong kasaysayan ay ang mga pagpapakahulugan ng Senyas na tinumbok ng pananaliksik na ito na nagpapakita ng mga katangiang Pilipino at nagpapahayag ng mga iba't ibang pangyayari base sa mga karanasan nila sa sariling bayan at ibayong dagat. Sa pangkalahatan, ang mga katangian at karanasang ito ay nagpapakita ng kabayanihan, katapangan, kapangyarihang pangkababaihan, Kalayaan, kaunlaran, kapayapaan, kadalubhasaan, pag-alay ng buhay para sa sariling bayan, pakikiisa sa kapwa sundalo, pagkakaisa ng mga mganggagawa tungo sa magandang kinabukasan, pagkabihasa ng mga manggagawa, karanasang Pilipino para sa pamilya at sa bayan, pagiging sensitibo sa mga paghihirap ng manggagawa, pagiging 'resilient' sa panahon ng kahirapan, pakikibaka ng mga protagonist para sa Kalayaan, paggunita sa araw ng Kalayaan, pakikipaglaban kasama ang mga Ameikano laban sa Hapon, pagkakaisa, pagtaas ng kamalayang Pilipino, pakikibaka para manumbalik ang demokrasya, pagpapatatag ng bansa, pakikibaka sa mga hamon, pagtulong sa mga mahihirap, paghihirap ng mga Pilipino na lalong nagpapatibay sa kanila, pag-uugnay sa mga Instik bilang bahagi ng pamayanang Pilipino, panunungkulan bilang paghahanda sa inaasam-asam na Kalayaan, panunungkulan para sa bayan, soberanya, damdaming maka-pamayanan, sagisag ng katotohanan at espiritu ng mga Pilipino, kuwento ng paglipat, kasangkapang nag-uugnay ng pamayanan (bangka), pagpapalitan ng kultura, pagkakaroon ng pinaka-unang patunay ng sistema sa pagsulat, may dugong artistiko, pagkahilig sa tato, simbolong pangkultural (Sarimanok), sagisag ng pagkaisa ng mga Pilipino (bahay-kubo), katangiang Pilipino gaya ng pagiging matalino at may angking talento, pagkakaroon ng pananampalataya ng mga sinaunang Pilipino, pagdiriwang ng kapistahan, pagsamba sa Batang Hesus, pagsayaw ng Sinulog at pagpapasalamat sa lahat ng mga biyayang natanggap ng 
Capulla, R. P., \& Demeterio, F. P. A., III

mga Pilipino. Ang lahat ng ito ay nagpapakita ng tunay na animong Pilipino at pagkabansa ng Pilipinas!

May relasyon ang mga Senyas sa pagkabansa ng Pilipinas. Ang mga Senyas, ang mga diskursong nakatago sa likod ng mga painting ay humuhubog sa pagkabansa ng Pilipinas at nagpapaigting ng damdaming makabansa.

Nagawa ang pagsusuring ito sa paggamit ng semiolohiya ni Barthes—nabigyang kahulugan at/o interpretasyon ang mga pangunahing materyal na icon. Natukoy ang Signified, Signifier at ang Senyas ng mga painting ng SiningSaysay. Napatunayan din na ang mga pampublikong espasyo gaya ng isang galeriya ay makapag-ambag din sa kasarinlan (people's pride). Ang pagdala ng sining malapit sa mga tao at publiko ay napakahahalaga upang lalong mapalakas, mabigyang kahulugan at mapaunlad ang kasaysayan. Paraan din ito kung saan ang mga tagapanood, tagasuporta at tagahanga ay makisali at makibahagi sa tinatawag na “pambuklikong diskurso.” Binuod din ng art gallery ang pambansang kultural na pagkakakilanlan.

Hindi rin madali ang karanasan ng mananaliksik upang mabuo ang pag-aaral na ito kasali na ang co-author sapagkat siya ang ang nagbigay-daan upang masuri ang mga obra ng SiningSaysay dala ang kanyang karanasan at husay sa paggamit ng hermeniutika nang sa gayon ay mabigyang hustisya ang mga magagaling na artist ng UP na kung wala sila, wala ring magaganap na diskurso.

Iminumungkahing ipagpatuloy ang nasimulang pagsusuri sa mga obra ng SiningSaysay at iba pang anyo ng sining sa bansa upang mas lalong mapaunlad ang kamalayang Pilipino at mapahalagahan ang kasaysayan lalo na ang kultura ng mahal na bayan.

\section{Mga Sanggunian}

Abrugar, V. Q. (2014). 8 Facts about the Battle of Leyte Gulf that will blow your mind. https://faq.ph/8-facts-about-the-battle-of-leyte-gulf-that-will-blow-your-mind/

OECD. (2017). The Philippines' migration landscape. In Interrelations between public policies, migration and development in the Philippines (pp. 41-65). OECD Publishing. https://doi.org/10.1787/9789264272286-6-en

Pascual, A. E. (2015). SiningSaysay: Philippine history in art. University of the Philippines System.

Pasong Tirad. (2015). In V. Almario (Ed.), Sagisag kultura (Vol 1). National Commission for Culture and the Arts.

Penaflor, C. (2017). The importance of paining and culture to an individual: Art is life. [Ang kahalagahan ng paining at kultura sa isang indibidwal. Art is life].

https://filipino1agroupblog.wordpress.com/2017/10/04/ang-kahalagahan-ng-sining-at-kultura-sa-isang-i ndibidwal

Reyno, M. C. G. (2012). Rizal's paternal lineage. National Historical Commission of the Philippines. https://nhcp.gov.ph/rizals-paternal-lineage/

Sakay, M. L. (2015). In V. Almario (Ed.), Sagisag kultura. (Vol 1). National Commission for Culture and the Arts.

SiningSaysay: Philippine history in art. (2015). University of the Philippines System.

Smith, A. (2015). Artists and nationalism. https://doi.org/10.1002/9781118663202.wberen053

Tapayang, M. (2015). In V. Almario (Ed.), Sagisag kultura. (Vol. 1). National Commission for Culture and the Arts. 